\title{
Analysing Challenges to Smart Waste Management for a Sustainable Circular Economy in Developing countries: A fuzzy DEMATEL study
}

\section{Honey Yadav}

Netaji Subhas Institute of Technology: Netaji Subhas University of Technology

Umang Soni ( $\square$ umangsoni.1@gmail.com )

Netaji Subhas University of Technology https://orcid.org/0000-0003-3583-311X

Girish Kumar

Netaji Subhas Institute of Technology: Netaji Subhas University of Technology

\section{Research}

Keywords: Smart Waste Management, Sustainable Circular Economy, Barriers, Fuzzy set theory, DEMATEL

Posted Date: April 5th, 2021

DOl: https://doi.org/10.21203/rs.3.rs-263855/v1

License: (c) (i) This work is licensed under a Creative Commons Attribution 4.0 International License. Read Full License

Version of Record: A version of this preprint was published at Smart and Sustainable Built Environment on November 12th, 2021. See the published version at https://doi.org/10.1108/SASBE-06-2021-0097. 


\title{
Analysing Challenges to Smart Waste Management for a Sustainable Circular Economy in Developing countries: A fuzzy DEMATEL study
}

\begin{abstract}
To improve the quality of life and achieve sustainability Internet of Things (IoT) plays a significant role. Waste can be converted to high value asset if treated properly with smart solutions. This study aims to develop an exploratory framework in the adoption of smart waste management in developing economies such as India analysing the various deferring parameters. To accomplish this aim the present study consists of two phases: In the first phase barriers in the adoption of IoT for smart waste management were identified after an extensive literature review and discussion with selected experts in this field. In the second phase the quantitative analysis using Fuzzy DEMATEL (Decision Making Trial and Evaluation Laboratory) method was performed on the selected barriers. The fuzzy DEMATEL methodology helps in prioritizing the most significant barrier by separating them into cause-effect group. The data were analysed on comparative basis based on two different perception to provide more detailed insight on the problems faced while smart waste management implementation. The results discloses that "Lack of government strict regulatory policies", "Lack of proper Financial planning” and "Lack of benchmarking processes" are among the most critical causal barriers towards IoT based smart waste management that are hindering the vision of efficient waste management system. Further "Difficulty in implementing innovative technologies" and "Absence of Dynamic Scheduling and Routing" fall under significant potential causal effect category. The most prominent effect barriers are "Lack of awareness among community", "Lack of source segregation and recycling commitment" and "Lack of service provider's" which was concluded in results considering the comparison parameters from different perspective. The study also suggest that the effect barriers can be overcome automatically with mitigating the causal barriers in the long run. The comparative details of the study will further help the policy makers, stakeholders and government experts to frame policies and interventions to eradicate the identified barriers towards an efficient and innovative system for waste handling.
\end{abstract}


Keywords: Smart Waste Management, Sustainable Circular Economy, Barriers, Fuzzy set theory, DEMATEL

\section{Introduction}

The vision of achieving sustainable development which provide improved quality of life for citizens and more efficient management of resources need revolutionary changes. The increasing population in countries have increased waste quantity which is the major concern. The unsuccessful and inefficient operations of waste management in cities have several reasons like collecting, disposing, routing vehicles and pollution that need to be monitored (Jacobsen et al., 2018). The technologies are envisioned to change the situation of urban development and provide aspiration towards efficient circular economy. Circular economy (CE) is referred as efficient use of natural resources. As the world realizes the necessity for sustainable utilization of resources the conventional model of linear economy (extract-make-dispose) has been transformed into circular economy (Zaman, 2015). Circular economy aims to adopt practices that reduce the waste generation and establish a closed-loop ecosystem for efficient utilization and consumption of resources (Korhonen et al. 2018). Moreover, Sustainable circular economic (SCE) model supports both the changes of designing and consumption perception, to produce products that can be reused, remanufactured and recycled. The existing literature also depicts the influence of waste management in achieving economic, social and environmental sustainability in long term is crucial (Xu et al. 2018). Cole et al. (2014) discussed the concept of zero-waste (ZW) management which provide waste prevention, valuation of all resources originated from wastes, high recycling levels and certain behavioural changes. Moh (2017) emphasis the potential of source segregation and recycling practices to attain circular economy concept. Hence the concept of circular economy and zero waste management goes side by side to create value from waste. The employment of smart technologies can help to attain the vision by involving infrastructure assistance and management decision-making. With IoT (Internet of thing) embedded system and increasing number of internet users in urban and rural areas, a transparent system with real time optimized waste collection can be achieved. The ongoing research in this domain mainly focuses on describing the technical assistance involved and their implementation, while it 
need to be examine through inter-disciplinary studies including engineering, urban sciences, ecological, economical and ethical domains as well. The present economy demands waste to be seen as resource. A 'resource' that can be recycled, reused and re-utilized in a manner where it leads maximum value recovery. Smart waste management define the waste handling with a transparent and technological methods. In smart cities, waste management is the inflow of waste value cycle in a flexible and efficient manner with real time monitoring. IoT allows the waste collection system to become connected and optimized while reducing costs and minimizing open dumping issues. An IoT based prototype works with sensors to measure the waste volume in containers or waste bins continuously, with facility to exchange information over the Internet. The data is collected and transmitted over the internet where intelligent and optimized algorithms are used to dynamically optimize the waste collection system. The results help in selecting better optimized route for waste collection and ensuring that waste is collected without affecting the environment and transported to proper segregation plants where disposal and recycling is done. The Table 1. Represent the table listing the technologies involved in smart waste management.

\section{Table 1. Smart technologies in smart waste management}

\begin{tabular}{|c|c|}
\hline Technologies & Application in smart waste management \\
\hline IoT sensor including NFC sensors, RFID tags and GPS sensors & $\begin{array}{l}\text { IoT is responsible for data collection, sensing, storing and processing by connecting the } \\
\text { physical or virtual device to the internet. IoT sensors can facilitate real-time monitoring of } \\
\text { the smart trash bins which provide information of each bin status and geographical location. }\end{array}$ \\
\hline Solar powered trash collectors using ultrasonic sensors & $\begin{array}{l}\text { Solar powered bins automatically compresses the trash into compact packet and ultrasonic } \\
\text { sensors helps in bin tracking and optimization. }\end{array}$ \\
\hline
\end{tabular}



and plan the recycling and value recovery activities.

Artificial Intelligence Automation can improve the sorting of the waste and identify the behavioural pattern of those who generate waste to make effective decision making.

The emission of poisonous gases from the open dumping field has taken the level of methane emission to an increasing level causing environmental issues like global warming, climate changes, pollution of ground water etc. Hence at the verge of global environment challenges we need to adopt changes in waste management system implementing technologies to solve the issues that are never seen with smart ways before. Also, the management of waste depends upon the level of population. Elevated population level leads to high waste generation and management issues. By 2030 it is estimated that $60 \%$ of the world's population will live in cities (United Nations, 2014). Solid waste management include various actions related to generation, storing, collecting, transport, processing and disposal. On the other hand in India due to rapid urbanization and increasing population the waste generation rate has been amplified at an alarming rate. In India, the waste management process is a decentralized system where local municipal corporations are responsible for the collection of waste from households, streets and other public areas. Municipal corporations are responsible for various functional responsibilities like supply of pure water, treatment of sewage, maintenance of hospitals and primary schools, naming streets and numbering houses, etc. The majority of solid waste are originated from the municipalities, they have thousands of tons per day containing all types of hazardous, organic and non-hazardous wastes. The harmful effects of these waste adversely affect the soil, ground-water and environment disbalancing the whole ecosystem. It include hospitals solid waste (80-90\% toxic) which is 
highly infectious waste (Himabindu et al. 2015). Also, when the world is fighting against COVID-19 pandemic, handling of waste is a serious issue that need to be improved. Electronic waste (all electronic gadgets) is estimated 50 million tonnes being discarded annually worldwide (IISD, 2019). Such huge quantity of waste need proper recycling while disposing. The solution to these issues were proposed via integration smart technologies such as IoT (Internet of Things) to waste management system. Table 2 (Appendix) shows the types, composition and sources of municipal solid waste (MSW).

Research regarding smart cities have already been done by many organization and been implemented as well. India launched smart city project in 2015 investing 98,000 crore including the adoption of smart waste management practices in selected cities, but still the improvement at ground level is low hence showing the need to examine the situation more deeply. Also, implementation of smart technologies at ground level in developing economies is still in the embryonic stage and deals with complex issues (Aljerf, 2018). The present research aims to analyse the developing economies such as India to adopt smart technologies and foresee the shortcomings. The study provide comprehensive insight about the barriers faced in the smart waste management implementation considering perception from real ground situation and to identify the interrelationship among the barriers. To achieve the aim Fuzzy DEMATEL method is considered as it facilitate to identify the cause-effect relationship among the barriers in a complex system. It is a visual structural model which helps to find the critical parameters in a system, divide them into cause and effect group and rank them for a strategic decision making. Therefore the present research was prepared to inform the decision-makers about the specific barriers that are hindering in smart waste management implementation. The research addressed the following two main objectives:

- To identify the significant barriers to the smart waste management implementation for an efficient CE in India

- To recognize how the key barriers are interacting and influencing the present stakeholders and how to make effective measures to improve the conditions for ecologically and economically sound waste management system in India. 
The rest of the paper is arranged as follows: Section I presents systematic literature review and data collection procedure. Section II consist methodology and importance of Fuzzy DEMATEL analysis. Section 3 discussed the results and summary obtained from the analysis. Section 4 discuss results and its managerial implications. Section 5 concluded the paper with the future suggestions and scope.

\section{Literature Review}

\subsection{Literature Review on cities those have adopted smart city concept}

Researches have shown that smart waste management adoption has been an open area for identifying major barriers that hinder its adoption. The below section comprises list of studies that highlight the benefits of adopting smart city concept including smart waste management around the world.

Table 3. Smart waste management studies (Countries/ cities)

\begin{tabular}{|l|l|l|}
\hline Literature & Implementation & Result \\
& Site & \\
\hline Calzada, 2018; March and & Barcelona Smart & The quality of life of citizen's improved with smart waste management (smart bins) infrastructure. \\
\hline Ribera-Fumaz, 2016 & City & Cleaner cities with less environmental pollution \\
\hline Yigitcanlar et al. 2020 & Sydney, Melbourne & Better sustainable environment with proper management of waste \\
& and Brisbane & \\
\hline
\end{tabular}




\begin{tabular}{|c|c|c|}
\hline & & $\begin{array}{l}\text { Improved quality of life to citizen's } \\
\text { Increased citizen awareness about technologies i.e. IoT, AI, and } 5 \mathrm{G}\end{array}$ \\
\hline Omar et al. 2016 & Malaysia & $\begin{array}{l}\text { Real-time platform is provided to waste collection operator to optimize operation time and cost. } \\
\text { Facilitate continuous monitoring to local authorities to ensure quality service delivery } \\
\text { Cleaner and healthier life to citizen's }\end{array}$ \\
\hline Mingaleva et al. 2020 & Russia & $\begin{array}{l}\text { Integration of smart technologies and sustainable development depend on level of participation of } \\
\text { citizens, increased engagement of people contribute to effective implementation and sustainable } \\
\text { development of cities } \\
\text { Capable to establish the concept of recycling economy which lead to green cities and cleaner } \\
\text { environment }\end{array}$ \\
\hline Yigitcanlar et al. 2019 & $\begin{array}{l}\text { Songo (Korea), } \\
\text { Masdar (UAE), } \\
\text { Amsterdam (The } \\
\text { Netherlands), San } \\
\text { Francisco (USA), } \\
\text { Brisbane (Australia) }\end{array}$ & $\begin{array}{l}\text { There is limited knowledge on smart city implication and its long term benefits on environment } \\
\text { The smart city concept deal with human/decision smartness rather than technological smartness. } \\
\text { Implementation of correct decisions and policies are critical aspect in smart urban development } \\
\text { Changing the view from technology centric to decision /policy centric }\end{array}$ \\
\hline
\end{tabular}


The mentioned studies put forward the need to adopt smart technologies concept to provide a better and sustainable future and to achieve the vision of efficient waste management system. Foreseeing the best time to collect garbage as well as synchronizing the number of vehicles collecting from the containers are of significant value, real time information about the containers also optimize the process of collecting waste. Therefore the developing economies need to focus on deferring parameters that lead to inefficient implementation of smart technologies. An extensive literature review is done to identify the prominent barriers while implementing smart waste management.

\section{Table 4. Barriers in implementation of Smart waste management}

\begin{tabular}{|l|l|l|}
\hline Literature & Purpose of the study & Barriers \\
\hline Sharma et al. 2020 & The aim of the study & The major barriers concluded are lack of regulatory norms, policies, direction, lack of \\
is to identify barriers & standardization and inadequate internet connectivity \\
to IoT adoption in & Recommended a need for in-depth study for barrier identification in smart cities projects in India \\
smart cities waste & \\
management in Indian & & \\
\hline
\end{tabular}




\begin{tabular}{|c|c|c|}
\hline & $\begin{array}{l}\text { context using MCDM } \\
\text { methods i.e. Total } \\
\text { Interpretive Structural } \\
\text { Modelling (TISM) } \\
\text { and Decision Making } \\
\text { Trial and Evaluation } \\
\text { Laboratory } \\
\text { (DEMATEL) }\end{array}$ & \\
\hline Kerdlap et al. 2019 & $\begin{array}{l}\text { The aim of the study } \\
\text { is to examine the } \\
\text { technical, research } \\
\text { related and } \\
\text { implementational } \\
\text { barriers in adopting } \\
\text { Zero } \\
\text { Manufacturing in } \\
\text { Singapore which leads } \\
\text { to circular economic }\end{array}$ & $\begin{array}{l}\text { IoT is capable to integrate waste stakeholders into a single network. } \\
\text { Source sorting of the waste is not present which causes heterogenous composition in collected } \\
\text { waste. } \\
\text { Waste bins are not able to measure the waste volume by material type which can improve the } \\
\text { waste planning significantly } \\
\text { An improved waste management chain is possible with IoT embedded network }\end{array}$ \\
\hline
\end{tabular}


model.

Bui et al. 2020
The aim of the study

is to identify barriers

towards sustainable

solid waste

management practices

using Fuzzy Delphi Insufficient research regarding solid waste management and need of more detailed study to method

The study identified

the barriers deferrin

the development of

smart cities in India

using Fuzzy AHP

(Analytic Hierarchy Governance barriers are the most significant in developing efficient smart city platform. Lack of

Process) method cooperation and coordination among city’s operational network, Lack of trust between governed and government, Poor public-private involvement are some of the parameters that are significant barriers in implementing solid waste management. 
the barriers of smart situation, failed past experience and inadequate infrastructure are concluded as most significant energy city in Accra barriers.

using two-step Fuzzy

DEMATEL

The main causal barriers included financial barrier, technological barriers, market barriers and policy barriers.

Cities with cleaner and sustainable environment is possible through integrating various alternatives such as information and communication technologies, renewable and other.

Lack of strict legal and regulatory framework, Inadequate availability of funds for infrastructure and technology, and lack of awareness about benefits of renewable energy technology and cost investment are also listed under critical causal barriers in the implementation of smart city platform.

Farooque et al. 2019

The study aims to In conclusion two main causal barriers are identified i.e. weak environmental regulations and identify barriers to enforcement of them and lack of market pressure.

circular food supply chain in China using

Lack of collaboration from supply chain channels also contribute in weak CE model adoption.

fuzzy DEMATEL The need of integrating CE in supply chain of food waste must be established.

approach

Research is needed to analyse the impact of IoT, Big Data Analytic and blockchains in 
establishing effective circular supply chain management especially in handling waste.

Effective recycling models should be adopted to extract maximum value from the waste

Kulkarni and Anantharama

Zhang et al 2019
The study address the repercussions

of environment as well as to virus transmission among the people

COVID-19 pandemic, the challenges and

opportunities

on

municipal solid waste

management

Automated waste treatment and disposal facilities are requisite to control the spill over effects

Efficient operational changes are needed to handle waste in the upcoming pandemic situations identify and analyse

barriers to smart

waste management

implementation

in Identification of barriers to smart waste management is significant to prioritize the actions that

Mishandling of infected waste can trigger the transmission rate

Decentralized waste management system and its integration with existing system is necessary to mitigate the potential risks

Smarter utilization of resources has to adopted to achieve sustainability

Diverse types of waste need to be managed by responsible and efficient waste management system to attain circular economic model

China to achieve been to be taken to improve the existing situations 
circular economic
model using Fuzzy

DEMATEL approach

Lack of regulatory measures, lack of environment education and cultural awareness about the environment protection and lack of market demands and pressure are concluded as key causal barriers.

Many more studies have shown the significance of Information and Communication (ICT) in monitoring and controlling the waste management. ICT allows the connectivity of devices and equipment to the Internet. Furthermore the data collected can be processed for optimizing routes and scheduling the collection process making it more flexible and transparent. For monitoring waste transportation Radio Frequency Identification (RFID) and Global Positioning System (GPS) with Global System for Mobile (GSM) techniques are applied. Some studies suggested that waste governance needs to identify waste stakeholders and their collaboration with the national authorities to achieve the goals for public health, resource recovery, environment and waste prevention (Guerrero et al. 2013). Rao et al. (2020) has also concluded that smart dustbins can improve the cleanliness of the cities via using ultrasonic sensors for automatic dustbin status monitoring.

China has been a leading economy in implementing smart technologies to attain circular economy. The main components of China emerging sustainable development is there national development policies. In India around 31.2\% of total population are staying in urban areas indicating a huge load of population to the metropolitan cities like Mumbai, Delhi, Bangalore, Indore, etc. Hence the issues of attaining sustainability and efficient waste management is a difficult task to handle by the urban local bodies. Doron, (2018) advocated the ignorance of people in India, demeaning the significance of cleaner and healthier system. Therefore the upcoming studies should analyse the actual field barriers in an exhaustive manner from different viewpoint to identify the main causal barriers that hinder the objective of circular economy with smart solutions. The mentioned literature review present a gap of studies conducted in developing economies with holistic approach to understand the hurdles in adopting smart solution to waste management. With the literature review it was also identified 
that major previous studies have not focused on the challenges faced by the developing economies in an integrated manner to support the efficient waste management. The selected barriers identified on the basis of the extensive literature review and validation from expert's and their short descriptions are listed in Table 5.

\section{Table 5. Barriers in adoption of SWM}

\begin{tabular}{|c|c|c|}
\hline Barriers & Description & References \\
\hline $\begin{array}{l}\text { 1. Lack of cluster- } \\
\text { based } \\
\text { planning }\end{array}$ & $\begin{array}{l}\text { Cluster-based planning (CBP) can provide better insight } \\
\text { of areas where smart waste management can be } \\
\text { implemented with successful outcomes and achieving } \\
\text { the goals of cleaner cities. CBP in implementing SWM } \\
\text { platform can help in targeting the high generating areas } \\
\text { and modernize the low growth areas. However, this } \\
\text { aspect is not given enough attention in implementation } \\
\text { SWM. }\end{array}$ & $\begin{array}{l}\text { Shah et al. 2018; Esmaeilian et al. 2018; Das et al. 2019; Zorpas } \\
2020 .\end{array}$ \\
\hline
\end{tabular}


technologies is one of the major barrier in the vision for adopting smart waste management platform. Unaware waste generators namely the general public amplifies the situations making it more complicated. The public participation to achieve an efficient solid waste management system is important in the era of emerging technologies.

3. Difficulty in The municipalities with continuously increasing waste implementing faces the challenge to improve their existing technology.

Zsigraiova et al., 2013; Hannan et al., 2015; Vasagade et al. 2020; innovative Every aspects of ICTs which can be utilized for an technology efficient SWM system should be focussed. Therefore, the challenge to find proper combination of ICTs by considering robustness, cost, complexity and environmental impacts is still open. Artificial intelligence with mathematical programming also help in developing new robust algorithms that facilitate optimal output and fast execution capability. 
4. Resistance people to change

of Littering and waste in streets is a major issue in developing countries that has a serious impacts towards environment and public health. There is no organized and scientifically planned segregation of waste either at the household level or at community level. The people perception towards the waste segregation at initial level and towards the workers need to change. Therefore, there is need of positive engagement such as integration of the informal sector into the society and change of attitude of people towards waste management issues.

5. Absence of Improvement to waste collection and transport routing dynamic scheduling can reduce environmental impact of open dumps and and routing
Kumar et al. 2017; Joshi and Ahmed, 2016; Vanapalli et al. 2020;

Kulkarni and Anantharama 2020.

Hannan et al 2020; Ali et al. 2020; Abdallah et al.2020; Vu et al. 2020. reducing cost and time parameters. The advantage of using dynamic scheduling and routing include collection cost and pollutant reduction, and collection efficiency improvement. Dynamic scheduling and routing have the highest potential to reduce the cost. It is also seen that 
using dynamic systems can provide lower operating and shortest collection routes.

6. Lack of proper The lack of financial monitoring and planning of Hannan et al. 2015; Zurbrugg et al. 2012; Aslam et al 2020; SBallal financial planning $\quad$ resources and establishing cost effective waste et al. 2019.

management system is one of the major barrier in envisaging improvement in existing systems. A study implemented in Bahir Dar, Ethiopia reveals that continuous analyses of financial data and monitoring are essential to understand the financial flows and attaining sustainable smart waste management system.

7. Lack

benchmarking

processes

8. Lack of source Segregation of waste at source point can help to build an segregation of Benchmarking local e-government procedures for recycling methods can be useful for city managers and researchers. Better practices should be identify from developed smart cities models. Moreover, efficient recycling methods and benchmarked practices can improve the quality of the recycled material.
Christ et al. 2017; Shmelev and Shmeleva 2019; Samarakkody et al. 2020; Moustaka et al. 2020. 
recycling

commitment

commitment

can maintain disposal and collecting process at feasible

level. Source-segregation of waste is usually not implemented in developing countries due to few door-

to-door collection and absence of motivation which leads to mixed form of waste in landfills sites.

Developing nations has major issue of lack of sourcesegregation as compared to developed nations where waste is more source separated.

9. Lack of To achieve sustainable consumption of resources and to Aslam et al. 2020; Tsai 2020; Chatterjee \& Kar 2018

government strict address environmental concerns public policies and

regulatory policies government should support. Government strict

regulatory measures focussing on general issues like

source-sorting and recycling will help to provide active

people support. It is known that due to government

stimulus a waste sorting behaviour can initiate among

the society though it might not be planned but it can 
create a difference.

10. Lack of service Waste management in developing countries can be seen

Shaukat et al. 2019; Lam and Yang 2020; Dolla and Laishram 2020;

providers

as a business opportunity initiating effective partnership Masood and Ahmad 2020;

between multiple stakeholders. Public-Private

Partnership can act as alternative tool of government

and management to handle the waste sector more

effectively. PPP is a credible alternative for

implementing smart cities projects including waste

management techniques when dealt with proper

consultation.

The above listed barriers were selected for further analysis with validation from the expert's in the study. The barriers were analysed using Fuzzy DEMATEL method to differentiate among cause-effect groups. The output of the method facilitates to identify the most causal barriers which can be mitigated with proper insight. To overcome the gap of comprehensive study the experts were included from different similar background to analyse the results from both the perception. The literature intend to make understand the managers and policy makers the importance of underline barriers influential and influenced impact.

\section{Methodology}


The fuzzy DEMATEL methodology is employed for this study to visualise the causal-effect relationship among the barriers. DEMATEL can also be used to reveal the overall degree of influence wielded by the respective factors Venkatesh et al. (2017). ISM and AHP can also be employed for similar study but it is not possible to determine the cause and effect relationship (Mangla et al. 2015). Though AHP is able to develop a hierarchical structure of the factors it is not possible to capture the interdependence relations between and among the factors. The DEMATEL is preferred over ISM due to the reason it is capable of determining the strength of relationship among and between the variables. (Govindan et al. 2017). However the DEMATEL is not able to handle the vagueness and uncertainty in the data. To overcome this limitation fuzzy concepts are integrated with the DEMATEL technique. Various decision making problems in recent literature have used Fuzzy DEMATEL because of its capability of uncovering complex causal relationships (Mangla et al. 2018). To remove vagueness of human judgements and to deal with ambiguity many scholars use DEMATEL with fuzzy logic as fuzzy set theory supplies solution to human uncertainties in these complex system. Fuzzy set theory is helpful in the situation which is unclear, vague and probabilistic in nature, and very useful in the process of decision-making through linguistic expressions (Ehsani et al. 2016). The present research applied the following steps, to analyse the barriers to smart waste management.

\section{Step 1: Construct a pair-wise comparison matrix}

In this step the participant are asked to assess the impact of the barrier $\mathrm{i}$ on the barrier $\mathrm{j}$ on the scale of 0 to $4(0=$ no influence, $1=$ very low influence, $2=$ low influence, $3=$ high influence and $4=$ very high influence). The information gathered is presented in the form a pair wise comparison matrix.

\section{Step 2: Generate the fuzzy direct- relation matrix}


In order to identify the model of the relations among the $\mathrm{n}$ criteria, an $\mathrm{n} \times \mathrm{n}$ matrix is first generated. The influence of the element in each row exerted on the element in each column of this matrix can be represented a fuzzy number. The response from multiple experts is converted into direct-relation matrix $\mathrm{z}$ using arithmetic mean.

$Z=\left[\begin{array}{ccc}0 & \cdots & \tilde{z}_{n 1} \\ \vdots & \ddots & \vdots \\ \tilde{z}_{1 n} & \cdots & 0\end{array}\right]$

Where, $\mathrm{z}_{\mathrm{n} 1}$ is the value obtained by arithmetic mean and then converted into linguistic value using Table 1

The following table shows the fuzzy scale used in the model.

Table 6: Fuzzy Scale (Farooque et al. 2020)

\begin{tabular}{|c|c|c|c|c|}
\hline Code & Linguistic terms & L & M \\
\hline 1 & No Effect & 0 & 0 \\
\hline 2 & Low effect & 0.25 & 0.25 \\
\hline 3 & Medium Effect & 0.25 & 0.5 \\
\hline 4 & High Effect & 0.5 & 0.5 \\
\hline 5 & Very High Effect & 0.75 \\
\hline
\end{tabular}




\section{Step 2: Normalize the fuzzy direct-relation matrix}

The normalized fuzzy direct-relation matrix can be obtained using the following formula (Source):

$\tilde{x}_{i j}=\frac{\tilde{z}_{i j}}{r}=\left(\frac{l_{i j}}{r}, \frac{m_{i j}}{r}, \frac{u_{i j}}{r}\right)$

Where $1, \mathrm{~m}$ and $\mathrm{u}$ are the fuzzy values identified from fuzzy direct relation matrix

$$
r=\max _{i, j}\left\{\max _{i} \sum_{j=1}^{n} u_{i j}, \max _{j} \sum_{i=1}^{n} u_{i j}\right\} \quad i, j \in\{1,2,3, \ldots, n\}
$$

Where, $\tilde{x}_{i j}$ is the normalized fuzzy value obtained for fuzzy direct relation matrix

\section{Step 3: Determine the fuzzy total-relation matrix}

To calculate the total-relation matrix the following formula is used:

$\tilde{T}=\lim _{k \rightarrow+\infty}\left(\tilde{x}^{1} \oplus \tilde{x}^{2} \oplus \ldots \oplus \tilde{x}^{k}\right)$

Where, $\mathrm{k}$ is a constant defined to infinity

If each element of the fuzzy total-relation matrix is expressed as $\tilde{t}_{\mathrm{ij}}=\left(\mathrm{l}_{\mathrm{ij}}^{\prime \prime} \mathrm{m}_{\mathrm{ij}}^{\prime \prime}, \mathrm{u}_{\mathrm{ij}}^{\prime \prime}\right)$ it can be calculated as follows:

$$
\left[l^{\prime \prime}{ }_{i j}\right]=x_{l} \times\left(I-x_{l}\right)^{-1}
$$




$$
\begin{aligned}
& {\left[m^{\prime \prime}{ }_{i j}\right]=x_{m} \times\left(I-x_{m}\right)^{-1}} \\
& {\left[u^{\prime \prime}{ }_{i j}\right]=x_{u} \times\left(I-x_{u}\right)^{-1}}
\end{aligned}
$$

Hence, the normalized matrix inverse is first calculated, and then it is subtracted from the matrix I (identity matrix), and finally the normalised matrix is multiplied by the resulting matrix.

Step 4: Defuzzify into crisp values: The CFCS (Converting Fuzzy data into Crisp Scores) method proposed by Opricovic and Tzeng (2003) is used to obtain crisp values of total-relation matrix. Wu and Lee (2007) stated that CFCS method provide better crisp values as compared to other methods. CFCS method determine the left and right values by fuzzy minimum and maximum and then calculate to final value. The steps CFCS method are as follows:

(i). Normalize the values:

$$
\begin{aligned}
& l_{i j}^{n}=\frac{\left(l_{i j}^{t}-\min l_{i j}^{t}\right)}{\Delta_{\min }^{\max }} \\
& m_{i j}^{n}=\frac{\left(m_{i j}^{t}-\min l_{i j}^{t}\right)}{\Delta_{\min }^{\max }} \\
& u_{i j}^{n}=\frac{\left(u_{i j}^{t}-\min _{i j}^{t}\right)}{\Delta_{\min }^{\max }}
\end{aligned}
$$

Where $1, \mathrm{~m}, \mathrm{u}$ are corresponding fuzzy values in each cell and 


$$
\Delta_{\min }^{\max }=\max u_{i j}^{t}-\min l_{i j}^{t}
$$

2. Calculating the upper and lower bounds of normalized values:

$$
\begin{gathered}
l_{i j}^{s}=m_{i j}^{n} /\left(1+m_{i j}^{n}-l_{i j}^{n}\right) \\
u_{i j}^{s}=u_{i j}^{n} /\left(1+u_{i j}^{n}-l_{i j}^{n}\right)
\end{gathered}
$$

3. Calculating total normalized crisp values:

$x_{i j}=\frac{\left[l_{i j}^{S}\left(1-l_{i j}^{S}\right)+u_{i j}^{S} \times u_{i j}^{S}\right]}{\left[1-l_{i j}^{S}+u_{i j}^{S}\right]}$

4. Combined crisp values: $x_{i j}=\left(\operatorname{minl}_{i j}+x_{i j} \Delta_{\min }^{\max }\right)$

From eq. (a) to (d) are used to calculate crisp value to form total-relation matrix.

\section{Step 5: Final output and create a causal relation diagram}

The next step is to find out the sum of each row and each column of T (in step 4). The sum of rows (D) and columns (R) can be calculated as follows: $D=\sum_{j=1}^{n} T_{i j}$ 
$R=\sum_{i=1}^{n} T_{i j}$

Then, the values of $\mathrm{D}+\mathrm{R}$ and $\mathrm{D}-\mathrm{R}$ can be calculated by $\mathrm{D}$ and $\mathrm{R}$, where $\mathrm{D}+\mathrm{R}$ represent the degree of importance of factor $\mathrm{i}$ in the entire system and $\mathrm{D}-\mathrm{R}$ represent net effects that factor $i$ contributes to the system. The horizontal vector $(\mathrm{D}+\mathrm{R})$ represents the degree of importance between each factor plays in the entire system. In other words, $(\mathrm{D}+\mathrm{R})$ indicates both factor i's impact on the whole system and other system factors' impact on the factor. Whereas, the vertical vector (D-R) represents the degree of a factor's influence on system. In general, the positive value of D-R represents a causal variable, and the negative value of D-R represents an effect. in terms of degree of importance

Case illustration applyintg DEMATEL is discuused in the next section.

\section{Case illustration}

The first phase include qualitative measure doing a systematic literature review and identifying the major barriers in smart waste management as well as interviewing the participants with open end questions about the knowledge of the topic. Before conducting the interviews the participants were provided with information sheet explaining the concepts of smart waste management and the related future opportunities in brief. A total 6 participants from different background participated in the study, participants belong to technology provider perspective i.e. companies that provide smart technology application in India and remaining working in the 'smart city' project initiated by government (Agra Smart City). To ensure the data efficacy and accuracy, the study include participants that had multiple years of experience in smart technologies and waste management system. The research participants shared their experience voluntarily and supported the research in active manner. All the included participants were at managerial level and presently working in the waste management sector. The participant was interviewed in March 2020-April 2020 either by an e-mail conversation or over the phone. Social business platform i.e. LinkedIn was used to reach the participants, each interview lasted for approx. 30-40 min for providing details insight about the study. 


\subsection{Data collection}

The data collection include the communication with expert's and extensive literature review done via reviewing scholarly journals. The study involve complex aspects of waste management including government bodies, NGOs, stakeholders, consumers, technologies providers and local urban bodies. The objective deals with identifying the key barriers faced at operational levels. Many companies like Scraptap, Hygienetech, ComePost, Ecocredible, etc. provide services for a decentralized waste management model with affordable prices enabling a Eco smart solution for urban areas. Also, the Government of India has initiated many programs like Swachh Bharat Abhiyan, Smart cities projects to develop an integrated vision under national strategies in promoting cleaner and ecofriendly waste management system. The participants were included from different backgrounds perspective i.e. from Government projects and Technology providers. The participant's performs managerial role in establishing smart waste management platform. Smart City project (2015) in India has been initiated at an extensive level, selecting 100 cities to be converted into smart cities handling the operation of the city with smart technologies which include waste management as well.

\subsection{DEMATEL application}

The results are observed on the basis of $\mathrm{D}+\mathrm{R}$ and $\mathrm{D}-\mathrm{R}$ values calculated for both the perception input. The expert's input from the questionnaire are evaluated separately using the steps and equations descried in Section 3.. The calculative matrix for each step are placed in appendices for both the perception. For Government project perception Table I, II, III and IV include the matrix respectively. Similarly, for Technology provider perception Table V, VI, VII and VIII represent the matrix to calculate the final result. The below section discuss the results obtained from each perspective separately followed with summary to results and its managerial implications. 


\section{Results and Discussion}

\subsection{Results from the Government project's Perspective}

The final cause-effect relation values from the total-relation matrix of the DEMATEL analysis (government perspective) are given in Table 5. The reason behind the slow adoption of smart waste management or negligence at ground level can be understood by analysing the results from different perspectives. The significance order of the barriers identified as ' $\mathrm{H} 9>\mathrm{H} 3>\mathrm{H} 8>\mathrm{H} 10>\mathrm{H} 2>\mathrm{H} 7>\mathrm{H} 1>\mathrm{H} 6>\mathrm{H} 5>\mathrm{H} 4$ ' obtained from analysing the $\mathrm{D}+\mathrm{R}$ values. "Lack of government strict regulatory policies" is the most prominent barrier whereas "Difficulty in implementing innovative technologies" and "Lack of source segregation and recycling" are the second and third most prominent barriers. The values of D+R and D-R are mapped in Fig 1 indicating the significant causeeffect relationship between the barriers. If the causal barrier is mitigated then the effect barrier is likely to be overcome automatically as per the interdependency among them. The diagram (Fig. 1) reveals that 'Lack of proper financial planning' and 'Lack of government strict regulatory policies' are the most significant causal barriers as their D-R values are the greatest. This suggest that while implementation of government's smart city project improper funds balancing and unacceptance from the people are critical aspect. In India there is a need of strict regulatory policies and proper enforcement to manage waste from resource point. These are causal barriers behind ineffective implementation of smart waste management under these projects. Furthermore, lack of benchmarking processes and difficulty in implementing innovative technologies are also causing the delay. There is a lack of standardized process between different regions to perform the waste management services in an efficient manner. The inadequacy in executing innovative technology to deal with social issues like waste disposals, energy management, health improving measures etc. at the ground level are still facing challenges for acceptance. Finally, lack of cluster based planning also turn out to be a causal parameter as proper planning ensures the success of the whole project and its efficiency to achieve the goal. Also, lack of government strict regulation has a significant effect on resistance of people to change. And lack of proper financial planning effect absence of dynamic routing and scheduling as apparently they can hinder new technological improvement in smart waste management system setup. Moreover, absence 
of regulatory policies can cause resistance from people to change their attitude about waste management. Lack of Government strict policies can also be the cause behind the limited integration of private service providers towards this issue. The results also reflected that lack of awareness among community is an effect barrier, and is influenced by lack of cluster-based planning and lack of government strict rules towards the waste monitoring. Clearly, the attitude and indulgence of people can be changed if the key causal barrier H9 (Lack of government regulatory strict policies) can be address effectively. To conclude the major causal barriers are lack of government strict regulating policies, lack of proper financial planning, lack of benchmarking processes, Difficulty in implementing innovative technologies and lack of cluster-based planning, and if the causal barriers are mitigated then the effects will also get improved according to the results.

\section{Table 7. Cause-effect results between the barriers from the government project's perspective}

\begin{tabular}{|c|c|c|c|c|}
\hline & $\mathrm{R}$ & $\mathrm{D}$ & $\mathrm{D}+\mathrm{R}$ & $\mathrm{D}-\mathrm{R}$ \\
\hline Lack of cluster-based planning & 2.643 & 2.692 & 5.335 & 0.049 \\
\hline Lack of awareness among community & 2.852 & 2.684 & 5.536 & -0.168 \\
\hline Difficulty in implementing innovative technologies & 2.784 & 2.843 & 5.627 & 0.059 \\
\hline Resistance of people to change & 2.591 & 2.409 & 5 & -0.182 \\
\hline Absence of Dynamic Scheduling and Routing & 2.547 & 2.491 & 5.037 & -0.056 \\
\hline Lack of Financial Planning & 2.382 & 2.754 & 5.136 & 0.372 \\
\hline Lack of Benchmarking process & 2.582 & 2.852 & 5.434 & 0.269 \\
\hline Lack of Segregation and recycling at source & 2.961 & 2.655 & 5.616 & -0.305 \\
\hline
\end{tabular}




\section{Figure 1. Cause-effect diagram for government project's perspective}

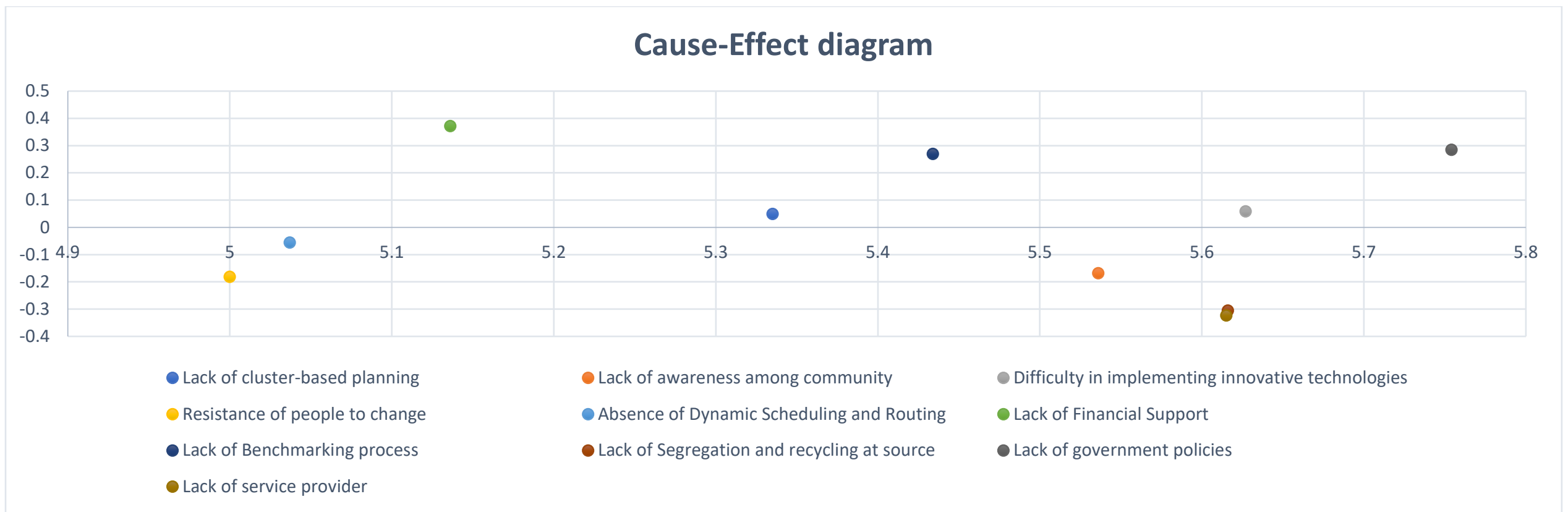

\subsection{Results from Technology contributor perspective}

Table 2. represent the results from the technology contributor perspective the most prominent barrier to smart waste management implementation are lack of government strict regulatory policies and lack of segregation and recycling at source. The significance order obtained according to the technology provider prospective is represented as: $\mathrm{H} 9>\mathrm{H} 8>\mathrm{H} 3>\mathrm{H} 2>\mathrm{H} 10>\mathrm{H} 6>\mathrm{H} 5>\mathrm{H} 1>\mathrm{H} 7>\mathrm{H} 4$ obtained from the values of $\mathrm{D}+\mathrm{R}$. The most significant barrier faced towards 
adoption is lack of government strict regulatory policies that is justified as if people take the waste management issue seriously as they do for other resources like electricity, the present scenario will improve in India. Fig. 2 depicts the D-R data that indicate lack of financial support and lack of benchmarking processes are the most influential barriers where absence of dynamic scheduling and routing, resistance of people to change and lack of government strict regulatory policies falls under the causal parameter. This suggest that from technology contributor perspective the main cause behind the slow adoption of smart technologies lies in both lack of financial support and lack in benchmarking processes. To employ smart waste management efficiently in India the financial support should be made available in equity manner. Moreover lack of benchmarking processes also turn out to be an important causal barriers indicating application of standardised methods while implementing smart technologies is an important parameter. With proper allocation of funds and standardised processes the smart waste management implementation can be done in an improved manner. The results also indicated that resistance of people towards new technologies and lack of strict government policies influence the implementation process, as if people will not become open to adopt new technologies there will be an resistance in implementation at ground level hence proper contribution within community level is important. The barriers that comes under the effect category are ' lack of cluster-based planning', 'lack of awareness among communities', 'difficulty in implementing technologies', 'lack of segregation and recycling at source' and lack of service provider. The conclusion can be made as with proper allocation of funds and standardised processes, the effects barriers such as private service providers and proper cluster-based planning can be addressed. 
Table 8. Cause-effect values shows the impact interdependencies between the barriers from the technology contributor perspective

\begin{tabular}{|c|c|c|c|c|}
\hline & $\mathrm{R}$ & $\mathrm{D}$ & $\mathrm{D}+\mathrm{R}$ & $\mathrm{D}-\mathrm{R}$ \\
\hline Lack of cluster based planning & 4.082 & 3.636 & 7.718 & -0.446 \\
\hline Lack of awareness among community & 4.187 & 4.133 & 8.32 & -0.053 \\
\hline Difficulty in implementing innovative technologies & 4.238 & 4.186 & 8.424 & -0.052 \\
\hline Resistance of people to change & 3.749 & 3.757 & 7.506 & 0.008 \\
\hline Absence of Dynamic Scheduling and Routing & 3.754 & 3.965 & 7.72 & 0.211 \\
\hline Lack of Financial support & 3.561 & 4.23 & 7.791 & 0.669 \\
\hline Lack of Benchmarking process & 3.66 & 4.015 & 7.675 & 0.354 \\
\hline Lack of segregation and recycling at source & 4.476 & 4.014 & 8.49 & -0.462 \\
\hline Lack of Government policies & 4.445 & 4.516 & 8.961 & 0.071 \\
\hline Lack of service provider & 4.127 & 3.828 & 7.955 & -0.299 \\
\hline
\end{tabular}


Figure 2. The cause-effect diagram for technology contributor perspective

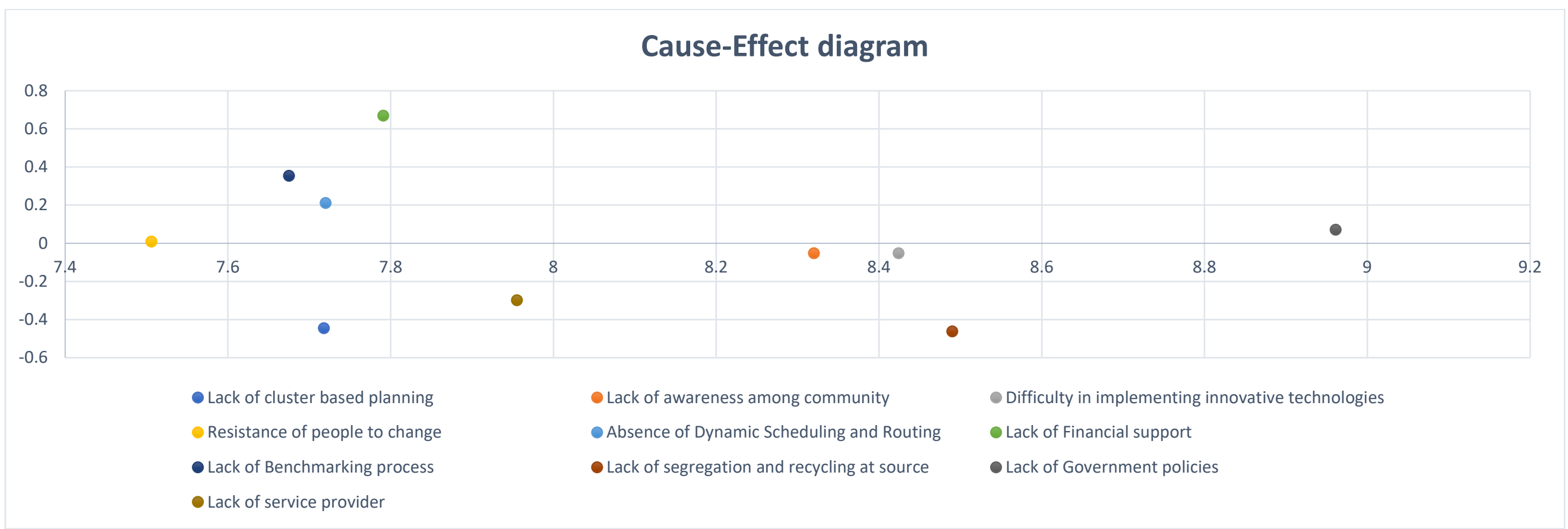


Figure 3. Cause-effect relationship among the barriers from both perception

Comparison of cause-effect barriers between Government and Technology perspective

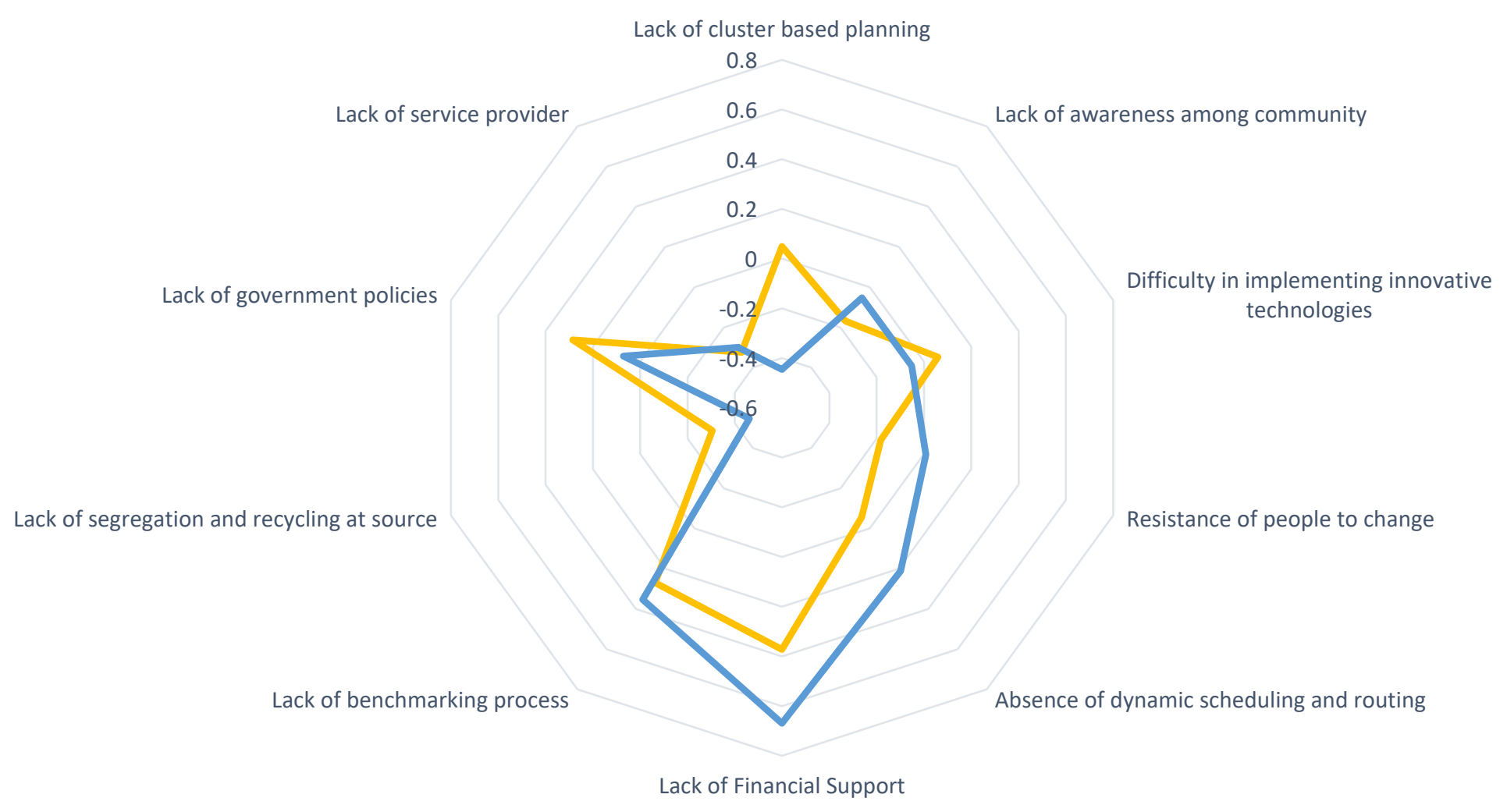




\section{Discussion and Summary}

The results obtained indicated similarities between technology contributor and government project perspective i.e. 'lack of government strict policies' is common and one of the significant adoption barrier. Both the stakeholders agreed that 'lack of proper financial planning' is an important causal barrier further lack of government strict regulatory policies and lack of benchmarking processes are also among the potential influential barriers that need to be mitigated to eliminate the later effects in the system. From technology contributor viewpoint 'Lack of awareness among people' is one of the important barrier in adopting smart waste management. People need to be get aware about the long term benefits, as without knowing they will not consider to accept it at ground level. The general attitude towards social issues like waste management need to be changed as the emerging technology of IoT is tech-social platform that can provide diverse benefits. The Government project participants gave more weightage towards 'Difficulty in Implementing Technology' and that is probably due to the fact that the participants are not expert in smart enabling technologies, so they sense more difficulty in technology dimensions. Moreover, hindrances from people as well as lack of exposure towards such smart platform is also responsible for present scenario. In India, the smart projects are proposed for various metropolitan cities but the implementation at ground level is still at challenging phase. While interviewing, participants revealed that while implementing smart waste management they face many issues such as inadequate resources, poor quality equipment's, improper planning and lack of people support. Hence the respondents gave major importance to 'Lack of source segregation and recycling commitment' as a hindering barrier towards the project. This can also be justified as to have an efficient system people need to participate actively into such processes and the acceptance has to be from both the sides. Both the stakeholders believe that regulatory policies is reasonable because waste management require strict measures and policies to be implemented so as to make active changes in the present system making it focussed for the community. The attitude of people towards waste problems also depends upon the policies formulated by government making it compulsory to adopt measures to reduce and recycle waste at individual level. Further cluster based planning is generally lacked in major technology projects as these projects fail to identify socio-economic barriers while implementation. In contrast technology contributor rated 
'Absence of Dynamic scheduling and routing' and 'Resistance of people to change' into causal groups indicating that technicians are working to overcome the limitation of IoT applications and the present barriers in large project implementation is lack of dynamic algorithms to enhance real time monitoring. Both the participants has rated 'Lack of awareness among community' as an effect barrier indicating that effective government policies can make people aware about new technologies and change their traditional methods to handle waste. Moreover, 'lack of source segregation and recycling' and 'lack of service provider' are also rated under effect groups indicating that these barriers can be overcome if the potential causal barriers are mitigated. The finding about the 'Difficulty in implementing technology' barrier also require special attention because it was identified as a causal barrier by government participants and an effect barrier by technology participant suggesting that technological challenges are not a problem from their perspective rather dynamic scheduling and routing and resistance from people are a more prominent cause.

Figure 3. depicts a pictorial insight from two different perspective. On behalf of these details the author proposed several prepositions: the first was strict regulatory policies should be emphasised. Muduli and Barve, (2012) supported that government regulations and public awareness regarding the waste issues can change the degrading situation in waste management sector providing suitable strategies to handle waste. Another study Priyadarshini et al. 2020 stated that waste management regulation for municipal corporation in India lack the alignment with circular economy principles and integration in policy framing. Mandal (2019) suggested a way forward by adopting the practices in other countries that had championed waste management. The country-wide campaign "Swachh Bharat Mission" (2014 to 2019) managed to transform the perception of people regarding waste management majorly but still the program lack to change the behaviour aspect towards new smart technology solutions, making people aware about the long-term benefits of these technologies (SWACHH BHARAT MISSION GRAMIN, 2017). Government programs regarding awareness about social issues and their interventions plays an important role and enhancing the citizen's participation towards more sustainable goals. Unlike regulations regarding electricity consumptions (Smart Meters) and bill payment while consuming electricity which have shown a significant improvement in energy consumption, waste management regulations should also be integrated 
with strict regulatory policies transforming the ground reality in India. The perception of people with "My Clean Home" should be change into "My Clean Country" making them flexible in accepting smart solutions toward waste management issues. Many research and case studies implemented in different countries have concluded that reward schemes have positive relationship with the waste management issues including minimizing waste, recycling at domestic level, collection of recyclables and many more (Afroz et al. 2011). Therefore policy-makers can adopt such reward schemes to develop behaviour change among communities especially in developing countries where there is an urgent need to adopt such practices.

The second conclusion was to handle lack of proper financial planning and benchmarking (prominent causal barriers). Guerrero et al. (2013) stated that waste services include high costs and expenditures as any other service in cities. Therefore proper administration of the provided funds are essential for an efficient sustainable waste management system. There is a huge amount proposed by the government in Smart City project, but they lack the proper distribution of funds in the project. From the government participant's interaction it was found that funds are misused and mismanaged in various aspects e.g. for the implementation of sensor for each area in Agra a private company was responsible however after the implementation the sensor does not work they were supposed to be but the private company did get the payment from the project via direct transfer from the government. Hence there was low quality after service and management by the firms due to the reason they get funds easily without crosschecking. Therefore proper distribution of funds should be done at each level of the project so that misusing of money is avoided as the resource in developing countries is limited and has to be used wisely. Whereas benchmarking is always considered as an important management tool to surpass the performance goals by learning from best practices and understanding the methods by which they are achieved. Solid waste benchmarking main purpose is to compare common elements in solid waste systems and to follow waste management from generation to disposal (NSWB, 2011). In 2010 the Ministry of Urban Development Government of India (MoUD) launched a Service Level Benchmarking (SLB) for managing solid waste management, storm water, wastewater and water supply (Service Level Benchmarking, 2010). The concept was proposed to help certain municipalities to predict the potential for economically efficient recycling and able to achieve better results. In Global scenario 
the recent National Sword Policy of China has declined the intake of contaminated recyclables. The policy includes a contamination limit of $0.5 \%$ on all other waste imports. Countries from high income, low income and middle income dump their recyclable waste to China recycling system with recent implication sword policy has created a tension that where this whole waste is going to get treated. It is estimated that by the year 2030,111 million MT of plastic waste will be displaced due to this policy (Greene, 2018). The problem can be overcome if the knowledge about recycling standards and quality recycling is achieved in developing economies. One of the way to improve the recycling process is to standardized processes. Innovative and economically sustainable methods has to be adopted by countries to practice recycling. Countries like Germany, Australia, United States of America have started adopting innovative recycling systems to manage a quality recycled products (Luczak, 2020). Hence Benchmarking the recycling practices in developing countries like India can help to implement best practices for recycling the waste from the initial level. With new standards of recyclable waste acceptance the countries have to improve the quality of recycling as well as focusing on better practices.

The third preposition drawn from the results suggest that in order to overcome the difficulty in implementing technology and innovative methods. Based on ground details of India an expert teams should be incorporated with projects on site so that they can give technical solutions to ground problems. On proposed prepositions the research indicated that strong enforcement of regulation and technology incorporated policies regarding waste management systems can result in better situation (Leal Filho et al. 2016). In comparison, municipal solid waste management of Germany have incorporated regulatory measures for collecting packaging waste, waste paper and bio-waste separately and strict ban on landfilling of non-pre-treated waste has been implemented in cities. Hence the role of government regulatory policies and awareness programs can be learned by many similar countries those have mastered the waste management system (Ahluwalia and Patel, 2018). The present government policies in India lacks the integration of smart technologies platform, circular sustainability, benchmarked recycling practices and waste management, hence the research propose strong relationship among barriers that are hindering the future smart world as well as provide roadmap to formulate policies keeping the stated barriers in mind. 


\section{Research Implications}

The critical causal barriers impose fundamental importance on the system as they effect it for long-term. The Indian government must take active measures to mitigate the barriers in implementing smart enabling technologies at ground level with maximum efficiency. The present research consist holistic insights of the barriers faced while implicating these project at ground level, hence policy-makers can decide accordingly the gaps that are present while the implementation process. Proper allocations of funds and strict regulatory measures including active participations of the community are the key enablers to enhance the quality of life with clean and sustainable environment. The vision of waste as an unwanted utility need to be change within the government system making it more sustainable and treating it as valuable resource. Many programs within India have managed to treat waste as an useful resource making the whole recycling process more efficient and valuable. In last decade India has made progress regarding waste management measures incorporating sustainable environment in its future vision. The Swach Bharat Abhiyan is one of the largest program implemented all over India creating awareness about the importance of handling waste efficiency. The integration of IoT enabled infrastructure in waste management process can further provide an advanced digitalized and connected platform to monitor the system efficiently. The IoT and related big data applications can play a key role in improving the process of waste sustainability development in future. The sensor based technology of IoT technology can collect large masses of urban data that can serve as an input to Big Data applications. Furthermore decision-makers can extract useful knowledge from the IoT data to provide relevant services in order to optimize urban processes and efficiency of ecosystem (Bibri, 2018). Also the advantages of smart enabling technologies should also be incorporated in present education system to aware the generation about the scope of the future smart cities. The prominent barriers revealed in the present study require immediate action from the government as well as research aspect so as to mitigate the long term effects on the systems. The overall barriers including difficulty in implementing 
technologies, lack of source segregation and recycling and lack of cluster based planning also inform the policy framing management to actively mitigate potential causal barriers to improve the long term adoption. The Indian government may consider programs and projects offering certain financial assistance to participants to further encourage the use and research in smart enabling technologies for improving the performance of the waste handling system.

\section{Conclusion}

India lags the approach to overcome the field barriers knowing that they differ from the mentioned one's. These barriers have interdependencies on each other. The research provide several contribution to the literature providing detailed insight on smart waste management project in India. Another contribution was the work has been prior in the field of comparative smart waste management studies considering the barriers from different perspective. Though smart enabling technologies bear the potential to improve the performance of the waste management system but still many developing countries struggle with barriers that hinder the implementation process. This research is well-timed as the present economy requires more digitalised solutions to handle the social utilities namely waste management, air quality monitoring etc. The research adopted a mixed methods approach to finalize the results firstly the barriers were selected through systematic literature review and then a quantitative approach was used to identify the cause-effect relationship among each other. The analysis was implemented considering responses from two different perspectives including government projects representatives and Technology contributor's in India. The research is focused within the context of India but it provides new details which can be helpful for other developing economies to relate. As the circular economy implementation becomes more necessary to provide better management of resources in long term, so well the barriers towards incorporating smart enabling technologies need to eliminate at initial level. The policy-makers can use the results for further programmes and policies consisting strict measure towards waste management system. Educational and awareness policies can initiate active participation from the community to accept the smart waste management implementation. Charge free smart dustbins can be implemented in rural areas to provide more engagement from the people i.e. community 
centric approach. Also, the research used the quantitative method to address the barrier and accordingly given priority. The barriers turn to be in two main categories namely cause and effect groups. The analysis believed that if causal barriers are eliminated by the management the effect barriers will get minimize accordingly. The present study can be referred by other developing countries to analyse the situation of waste management and focus on causal barriers identified in the study.

Moreover to overcome the limitations future work can focus towards collecting data from other relevant sources including surveys and various field stakeholders dealing with smart waste solutions to provide further results regarding the critical parameters. The research included representative from industry and government perspective further studies can be done including sectors who have implemented smart waste management and can provide real experience with various issues encountered after implementing smart waste management. The qualitative analysis can further be done using other qualitative methods like Delphi Method to provide the identification of barriers more exclusively. 


\section{$\underline{\text { Declarations }}$}

\section{$\underline{\text { Availability of Data and Materials }}$}

The data was collected from two different domains including expert's from Smart City Project and expert's from Technical domain including companies like IoTracX and others. The data provided below is used to complete the proposed methodology in the paper. The scale was defined in the questionnaire for the expert's.

\begin{tabular}{|l|l|}
\hline NOTE: & For rating each Criteria \\
& W.r.t \\
\hline No Effect (NO) & $\mathbf{0}$ \\
\hline Low Effect (L) & 1 \\
\hline Medium Effect (M) & 2 \\
\hline High Effect(H) & 3 \\
\hline Very High Effect (VH) & 4 \\
\hline
\end{tabular}

\section{Smart City Expert's}

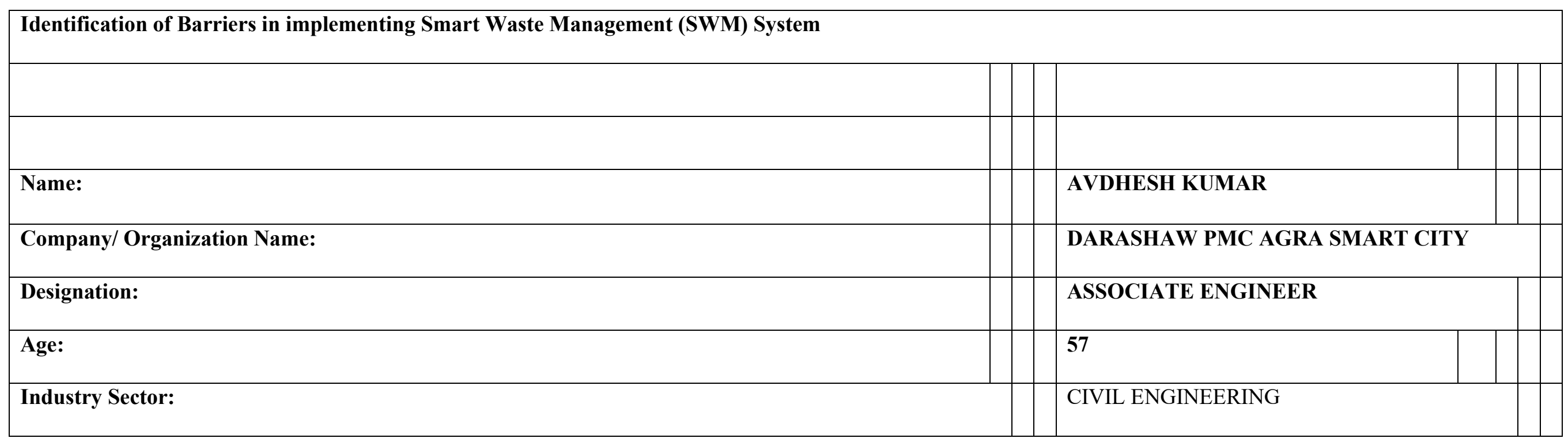




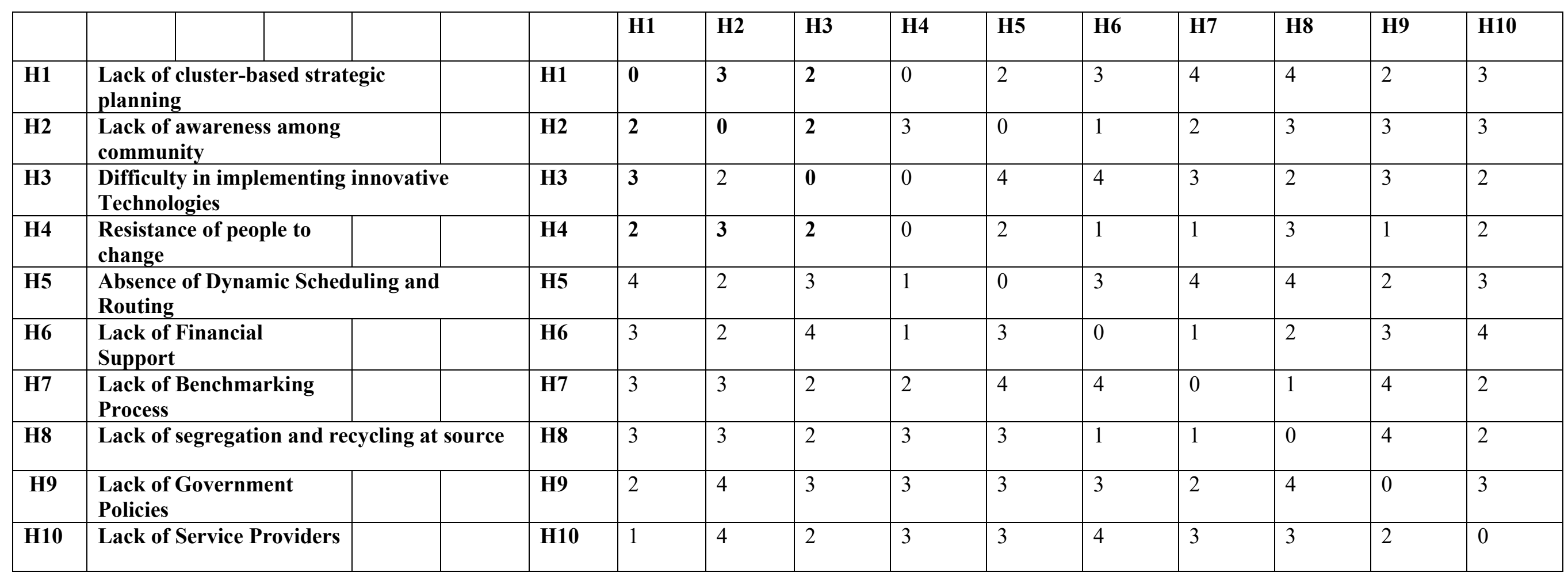

\begin{tabular}{|c|c|}
\hline \multicolumn{2}{|c|}{ Identification of Barriers in implementing Smart Waste Management (SWM) System } \\
\hline & \\
\hline & \\
\hline Name: & Pawan Singh \\
\hline Company/ Organization Name: & Darashaw \& company Pvt Lmt \\
\hline Designation: & Landscape Architect \\
\hline Age: & 28 \\
\hline
\end{tabular}




\begin{tabular}{|l|l|l|}
\hline Industry Sector: & Infrastructure & \\
\hline & & \\
\hline
\end{tabular}

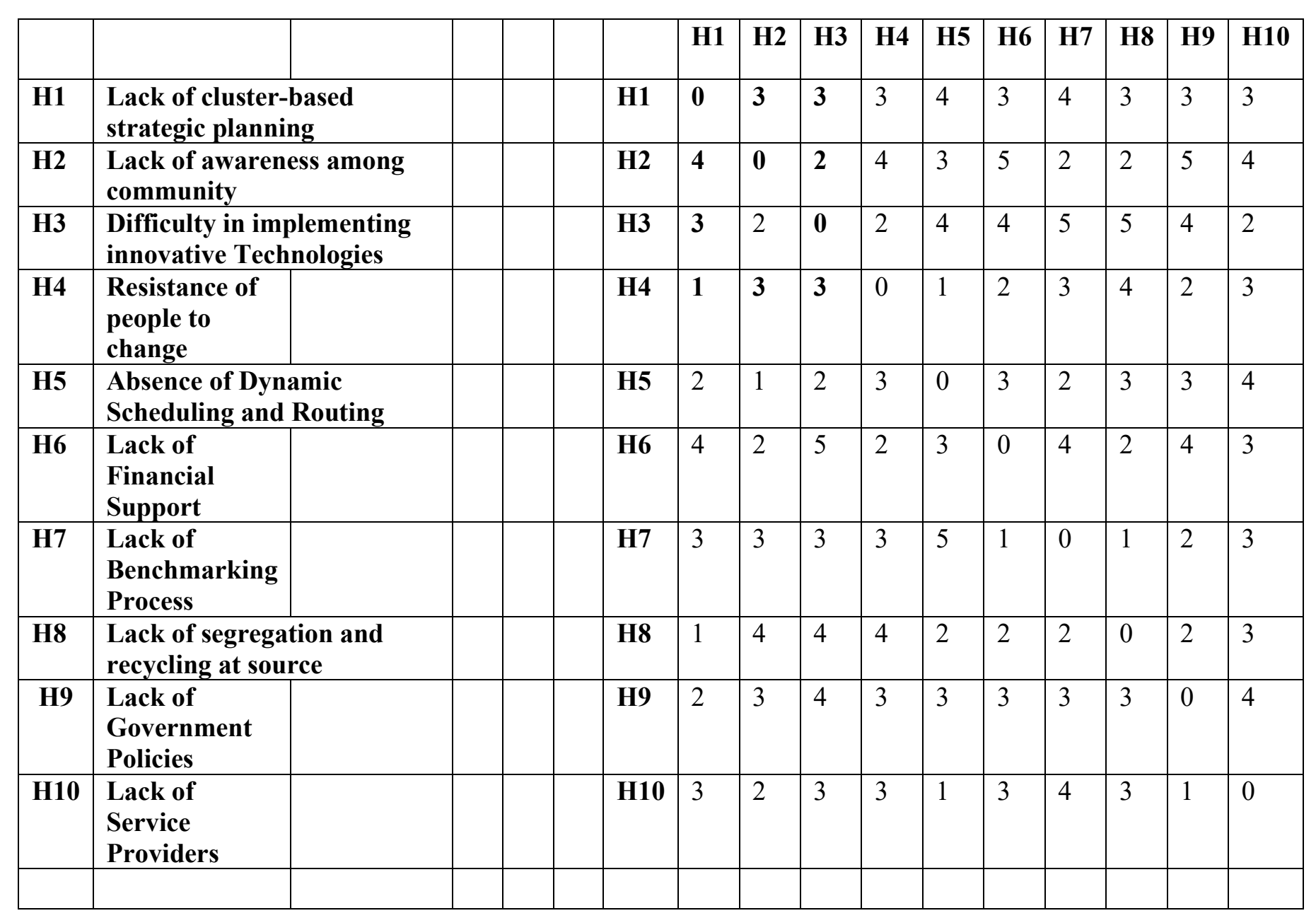

Identification of Barriers in implementing Smart Waste Management (SWM) System 


\begin{tabular}{|c|c|c|c|c|c|c|c|c|c|c|c|c|c|}
\hline \multicolumn{2}{|c|}{ Name: } & \multicolumn{2}{|c|}{ Nikhil Thool } & & & & & & & & & & \\
\hline \multicolumn{2}{|c|}{ Company/ Organization Name: } & & & & \multicolumn{3}{|c|}{$\begin{array}{l}\text { Darashaw } \\
\text { Consulting Pvt } \\
\text { limited }\end{array}$} & & & & & & \\
\hline \multicolumn{2}{|c|}{ Designation: } & & \multicolumn{2}{|c|}{$\begin{array}{l}\text { Senior } \\
\text { Associate }\end{array}$} & & & & & & & & & \\
\hline \multicolumn{2}{|l|}{ Age: } & 31 & & & & & & & & & & & \\
\hline \multicolumn{3}{|c|}{ Industry Sector: } & \multicolumn{2}{|c|}{ Consulting } & & & & & & & & & \\
\hline & & & & H1 & $\mathbf{H 2}$ & $\mathbf{H 3}$ & H4 & H5 & H6 & $\mathbf{H 7}$ & H8 & H9 & H10 \\
\hline H1 & \multicolumn{2}{|c|}{$\begin{array}{l}\text { Lack of cluster-based strategic } \\
\text { planning }\end{array}$} & H1 & $\mathbf{0}$ & 3 & 4 & 4 & 3 & 3 & 4 & 3 & 4 & 3 \\
\hline H2 & \multicolumn{2}{|l|}{$\begin{array}{l}\text { Lack of awareness among } \\
\text { community }\end{array}$} & $\mathbf{H 2}$ & 2 & $\mathbf{0}$ & 3 & 2 & 3 & 2 & 2 & 3 & 3 & 2 \\
\hline H3 & \multicolumn{2}{|c|}{$\begin{array}{l}\text { Difficulty in implementing innovative } \\
\text { Technologies }\end{array}$} & H3 & 4 & 3 & $\mathbf{0}$ & 3 & 2 & 3 & 2 & 2 & 3 & 2 \\
\hline H4 & $\begin{array}{l}\text { Resistance of people to } \\
\text { change }\end{array}$ & & H4 & 4 & 3 & 3 & 0 & 3 & 4 & 3 & 2 & 3 & 4 \\
\hline H5 & \multicolumn{2}{|c|}{$\begin{array}{l}\text { Absence of Dynamic Scheduling and } \\
\text { Routing }\end{array}$} & H5 & 2 & 2 & 3 & 2 & 0 & 2 & 3 & 3 & 2 & 3 \\
\hline H6 & $\begin{array}{l}\text { Lack of Financial } \\
\text { Support }\end{array}$ & & H6 & 3 & 4 & 3 & 4 & 4 & 0 & 3 & 4 & 4 & 3 \\
\hline H7 & $\begin{array}{l}\text { Lack of Benchmarking } \\
\text { Process }\end{array}$ & & H7 & 4 & 4 & 3 & 4 & 4 & 3 & 0 & 4 & 4 & 3 \\
\hline H8 & \multicolumn{2}{|c|}{ Lack of segregation and recycling at source } & H8 & 2 & 1 & 2 & 3 & 2 & 2 & 3 & 0 & 2 & 2 \\
\hline H9 & $\begin{array}{l}\text { Lack of Government } \\
\text { Policies }\end{array}$ & & H9 & 3 & 4 & 3 & 4 & 3 & 3 & 4 & 3 & 0 & 3 \\
\hline H10 & Lack of Service Providers & & H10 & 3 & 3 & 4 & 3 & 4 & 3 & 2 & 4 & 4 & 3 \\
\hline & & & & & & & & & & & & & \\
\hline
\end{tabular}




\section{Technical Expert's}

\section{Identification of Barriers in implementing Smart Waste Management (SWM) System}

Name: Hetal Sorathia

\section{Company/ Organization Name: Swachh Bharat Mission Urban Gujarat}

\section{Designation: Manager Project}

Age: 35

\section{Industry Sector: State Government}

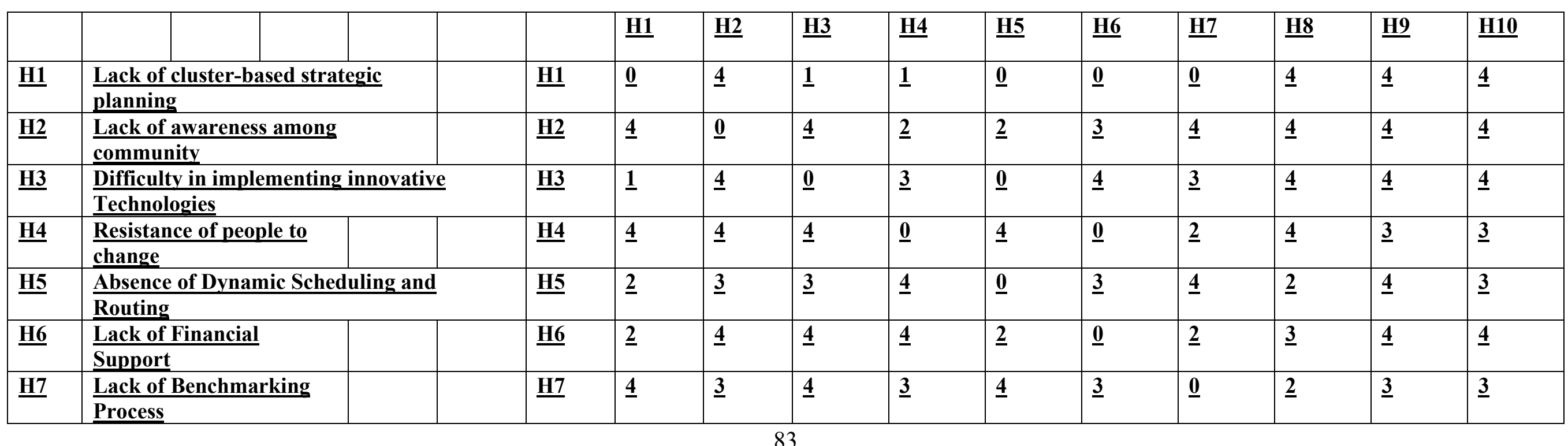




\begin{tabular}{|c|c|c|c|c|c|c|c|c|c|c|c|c|c|}
\hline$\underline{\mathrm{H} 8}$ & Lack of segregation and $\mathrm{r}$ & & $\underline{\mathrm{H} 8}$ & 4 & 4 & $\underline{2}$ & $\underline{4}$ & $\underline{3}$ & $\underline{2}$ & 4 & $\underline{\mathbf{0}}$ & $\underline{\mathbf{3}}$ & $\underline{2}$ \\
\hline$\underline{\mathrm{H} 9}$ & $\begin{array}{l}\text { Lack of Government } \\
\text { Policies }\end{array}$ & & $\underline{\mathrm{H} 9}$ & 4 & 4 & 4 & $\underline{4}$ & $\underline{4}$ & $\underline{4}$ & 4 & $\underline{4}$ & $\underline{\mathbf{0}}$ & 4 \\
\hline$\underline{\mathrm{H10}}$ & Lack of Service Providers & & $\underline{\mathrm{H10}}$ & $\underline{\mathbf{3}}$ & $\underline{\mathbf{3}}$ & $\underline{2}$ & $\underline{4}$ & $\underline{2}$ & $\underline{2}$ & 1 & $\underline{4}$ & $\underline{3}$ & $\underline{\mathbf{0}}$ \\
\hline
\end{tabular}

\begin{tabular}{|l|l|l|l|l|}
\hline \multicolumn{1}{|l|}{ Identification of Barriers in implementing Smart Waste Management (SWM) System } \\
\hline & & & \\
\hline$\underline{\text { Name: }}$ & & & \\
\hline Company/ Organization Name: & Dr. Umang Soni & & & \\
\hline Designation: & & $\underline{\text { NSUT }}$ & \\
\hline$\underline{\text { Age: }}$ & & $\underline{\text { Assistant Prof }}$ & & \\
\hline Industry Sector: & & $\underline{39}$ & & \\
\hline & & $\underline{\text { Academics }}$ & & \\
\hline & & & & \\
\hline
\end{tabular}

\begin{tabular}{|c|c|c|c|c|c|c|c|c|c|c|c|c|}
\hline & & & $\underline{\mathrm{H1}}$ & $\underline{\mathrm{H} 2}$ & $\underline{\mathrm{H} 3}$ & $\underline{\mathrm{H} 4}$ & $\underline{\mathrm{H} 5}$ & $\underline{\mathrm{H} 6}$ & $\underline{\mathrm{H} 7}$ & $\underline{\mathrm{H} 8}$ & $\underline{\mathrm{H} 9}$ & $\underline{\mathrm{H10}}$ \\
\hline$\underline{\mathrm{H} 1}$ & $\begin{array}{l}\text { Lack of } \\
\text { cluster-based } \\
\text { strategic } \\
\text { planning }\end{array}$ & $\underline{\mathrm{H} 1}$ & $\underline{0}$ & 1 & $\underline{3}$ & 1 & $\underline{2}$ & $\underline{2}$ & $\underline{0}$ & 4 & $\underline{3}$ & $\underline{2}$ \\
\hline$\underline{\mathbf{H} 2}$ & $\begin{array}{l}\text { Lack of } \\
\text { awareness } \\
\text { among } \\
\text { community } \\
\end{array}$ & $\underline{\mathrm{H} 2}$ & $\underline{\mathbf{3}}$ & $\underline{0}$ & $\underline{\mathbf{3}}$ & 4 & $\underline{2}$ & $\underline{2}$ & $\underline{\mathbf{3}}$ & 4 & 4 & 1 \\
\hline$\underline{\mathbf{H} 3}$ & $\begin{array}{l}\frac{\text { Difficulty in }}{\text { implementing }} \\
\text { innovative } \\
\text { Technologies } \\
\end{array}$ & $\underline{\mathrm{H3}}$ & 1 & $\underline{2}$ & $\underline{0}$ & $\underline{3}$ & 1 & 4 & $\underline{2}$ & $\underline{3}$ & 4 & $\underline{2}$ \\
\hline$\underline{\mathrm{H} 4}$ & $\begin{array}{l}\frac{\text { Resistance of }}{\text { people to }} \\
\frac{\text { change }}{}\end{array}$ & $\underline{\mathrm{H} 4}$ & $\underline{2}$ & $\underline{3}$ & $\underline{2}$ & $\underline{0}$ & 1 & $\underline{2}$ & & $\underline{2}$ & 4 & 1 \\
\hline$\underline{\mathrm{H5}}$ & Absence of & $\underline{\mathrm{H} 5}$ & $\underline{1}$ & $\underline{1}$ & $\underline{3}$ & $\underline{1}$ & $\underline{\mathbf{0}}$ & $\underline{\mathbf{3}}$ & $\underline{2}$ & $\underline{3}$ & $\underline{1}$ & $\underline{\mathbf{3}}$ \\
\hline
\end{tabular}




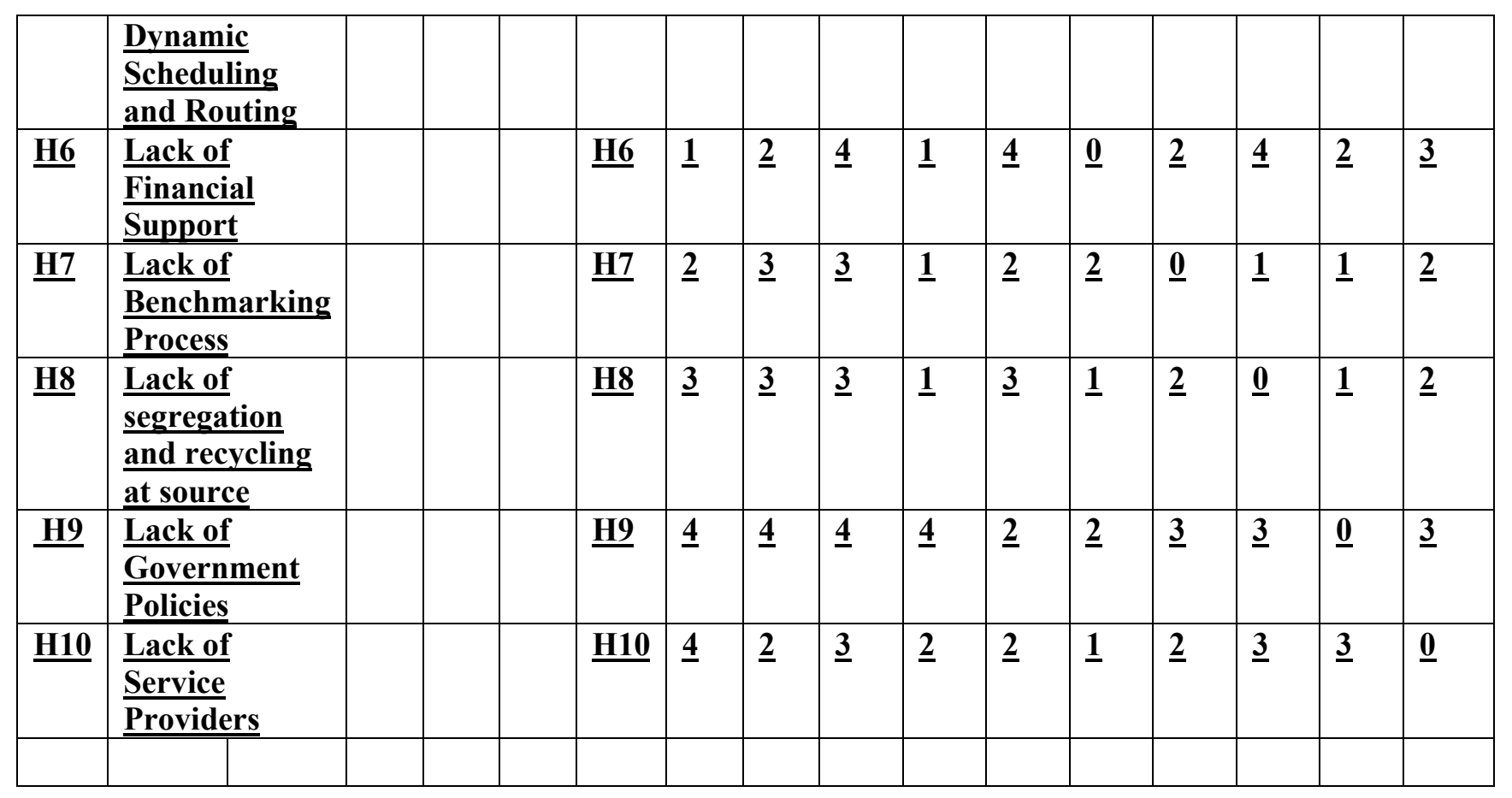

\begin{tabular}{|c|c|c|c|}
\hline $\begin{array}{l}\text { Identification of Barriers in imp } \\
\text { Management (SWM) System }\end{array}$ & $\mathrm{Sm}$ & t Waste & \\
\hline Name: & $\underline{\text { Om }}$ & $\frac{\text { irdeep }}{\text { Bhatia }}$ & \\
\hline Company/ Organization Name: & & & $\underline{\text { IoTracX }}$ \\
\hline Designation: & & $\frac{\text { Project }}{\text { Designer }}$ & \\
\hline Age: & $\underline{23}$ & & \\
\hline Industry Sector: & & & \\
\hline & & & \\
\hline
\end{tabular}

\begin{tabular}{|c|c|c|c|c|c|c|c|c|c|c|c|c|}
\hline & & & $\underline{\mathrm{H1}}$ & $\underline{\mathrm{H} 2}$ & $\underline{\mathrm{H} 3}$ & $\underline{\mathrm{H4}}$ & $\underline{\text { H5 }}$ & $\underline{\text { H6 }}$ & $\underline{\mathrm{H} 7}$ & $\underline{\mathrm{H} 8}$ & $\underline{\mathrm{H9}}$ & $\underline{\text { H10 }}$ \\
\hline$\underline{\text { H1 }}$ & $\begin{array}{l}\text { Lack of cluster-based } \\
\text { strategic planning }\end{array}$ & $\underline{\mathrm{H1}}$ & $\underline{\mathbf{0}}$ & $\underline{4}$ & $\underline{\mathbf{3}}$ & $\underline{\mathbf{0}}$ & $\underline{\mathbf{3}}$ & $\underline{4}$ & $\underline{\mathbf{3}}$ & $\underline{4}$ & $\underline{\mathbf{3}}$ & $\underline{\mathbf{3}}$ \\
\hline
\end{tabular}




\begin{tabular}{|c|c|c|c|c|c|c|c|c|c|c|c|c|}
\hline$\underline{\mathrm{H} 2}$ & $\begin{array}{l}\text { Lack of awareness among } \\
\text { community }\end{array}$ & $\underline{\mathrm{H} 2}$ & $\underline{\mathbf{3}}$ & $\underline{\mathbf{0}}$ & $\underline{2}$ & 1 & 1 & 1 & $\underline{2}$ & 4 & $\underline{\mathbf{3}}$ & $\underline{2}$ \\
\hline$\underline{\mathbf{H} 3}$ & $\begin{array}{l}\text { Difficulty in } \\
\text { implementing innovative } \\
\text { Technologies }\end{array}$ & $\underline{\mathrm{H} 3}$ & $\underline{\mathbf{3}}$ & $\underline{\mathbf{3}}$ & $\underline{0}$ & 1 & 4 & 4 & 4 & $\underline{2}$ & 4 & $\underline{\mathbf{3}}$ \\
\hline$\underline{\mathrm{H} 4}$ & \begin{tabular}{l|l} 
Resistance of \\
people to \\
change
\end{tabular} & $\underline{\mathrm{H} 4}$ & $\underline{2}$ & $\underline{3}$ & $\underline{2}$ & $\underline{0}$ & 1 & 1 & 1 & 4 & $\underline{2}$ & $\underline{3}$ \\
\hline$\underline{\mathrm{H} 5}$ & $\begin{array}{l}\text { Absence of Dynamic } \\
\text { Scheduling and Routing }\end{array}$ & $\underline{\text { H5 }}$ & $\underline{2}$ & $\underline{2}$ & $\underline{\mathbf{3}}$ & 4 & $\underline{\mathbf{0}}$ & 4 & $\underline{\mathbf{3}}$ & $\underline{\mathbf{3}}$ & $\underline{2}$ & 1 \\
\hline$\underline{\mathrm{H} 6}$ & \begin{tabular}{l|l} 
Lack of & \\
Financial \\
Support
\end{tabular} & $\underline{\mathrm{H} 6}$ & 4 & $\underline{2}$ & 4 & $\underline{\mathbf{3}}$ & $\underline{4}$ & $\underline{0}$ & $\underline{2}$ & $\underline{2}$ & 4 & $\underline{2}$ \\
\hline$\underline{\mathrm{H} 7}$ & \begin{tabular}{l|} 
Lack of \\
Benchmarking \\
Process
\end{tabular} & $\underline{\text { H7 }}$ & $\underline{\mathbf{3}}$ & $\underline{2}$ & $\underline{\mathbf{3}}$ & $\underline{2}$ & $\underline{4}$ & $\underline{\mathbf{3}}$ & $\underline{\mathbf{0}}$ & $\underline{2}$ & $\underline{\mathbf{3}}$ & $\underline{\mathbf{3}}$ \\
\hline$\underline{\mathrm{H} 8}$ & $\begin{array}{l}\text { Lack of segregation and } \\
\text { recycling at source }\end{array}$ & $\underline{\mathrm{H} 8}$ & 4 & $\underline{3}$ & $\underline{2}$ & $\underline{2}$ & $\underline{\mathbf{3}}$ & $\underline{2}$ & $\underline{2}$ & $\underline{\mathbf{0}}$ & 4 & $\underline{3}$ \\
\hline$\underline{\mathrm{H} 9}$ & $\begin{array}{l}\text { Lack of } \\
\text { Government } \\
\text { Policies }\end{array}$ & $\underline{\mathrm{H} 9}$ & $\underline{2}$ & $\underline{2}$ & 1 & 4 & $\underline{3}$ & 1 & $\underline{3}$ & $\underline{3}$ & $\underline{0}$ & 4 \\
\hline$\underline{\mathrm{H} 10}$ & $\begin{array}{l}\text { Lack of Service } \\
\text { Providers }\end{array}$ & $\underline{\mathrm{H} 10}$ & $\underline{2}$ & 1 & $\underline{2}$ & $\underline{\mathbf{3}}$ & 4 & $\underline{2}$ & $\underline{2}$ & $\underline{2}$ & $\underline{\mathbf{3}}$ & $\underline{0}$ \\
\hline
\end{tabular}

\section{Competing Interests:}

There is no conflict of interest for the present study.

\section{Funding:}

There is no funding agency for the present paper.

\section{Author's Contribution:}

The author's contribution can be expressed through immense hard work and support through their kind guidance. There is a significance contribution in the modelling and analysis of the methodologies stated. Moreover, expert's contribution has also been privileged by the author on the basis of their experience and intelligence in the industry.

\section{Acknowledgements:}


The study has been initiated under the guidance of the author's.

\section{Author's Information:}

\section{Dr. Umang Soni}

Umang Soni is assistant Professor at Division of manufacturing process and automation engineering at NSIT. He has $8+$ years of Industrial, research and teaching experience, which includes organizations like Wipro technologies (Bangalore), Bharat Forge (Pune). His area of expertise includes supply chain management, operations management and risk management.

Educational Qualification:

B.E. (Mechanical Engineering)-RGPV University

M.E (Manufacturing Systems \& engineering)- BITS Pilani

Ph.D. (Industrial Engg)- IIT Delhi

\section{Dr. Girish Kumar}

G. Kumar currently works at the Department of Mechanical and Production Engineering, Delhi Technological University. His interest area includes research in Reliability Engineering and Industrial Engineering. He has 15 years of experience in teaching and research; presently guiding $5 \mathrm{PhD}$ students and supervised $21 \mathrm{~B}$. Tech and $07 \mathrm{M}$. Tech projects. For about 5 years, He had worked as Production Manager in the Indian Ordnance Factory Organization, Ministry of Defence, Government of India.

Educational Qualification:

Ph.D. (Reliability Engineering), Indian Institute of Technology Delhi

Dissertation: Availability analysis of mechanical systems with dependencies and select maintenance policies.

M. Tech. (Industrial Tribology and Maintenance Engineering), Indian Institute of Technology Delhi

B.Sc. Engineering (Mechanical Engineering), Aligarh Muslim University

\section{Ms. Honev Yadav}

Honey Yadav is currently pursuing her PhD. From Indian Institute of Technology, Delhi in Telecom Management. She has one year industrial experience in Wipro Limited as a Project Engineer. Also, She had one year teaching experience as a Lecturer in Bhaavya Technical Institute. Her interest areas include waste management, e-commerce, digital marketing.

Educational Qualification:

B.Tech. (Electrical and Electronic Engineering)- Galgotia's University

M.Tech (Engineering Management)- NSIT, Delhi

Ph.D. (Telecom Management)- IIT Delhi (Pursuing) 


\section{REFERENCES}

1. Jacobsen, R., Willeghems, G., Gellynck, X., Buysse, J., 2018. Increasing the quantity of separated post-consumer plastics for reducing combustible household waste: the case of rigid plastics in Flanders. Waste Manag. 78, $708 \mathrm{e} 716$.

2. Zaman, A.U., 2015. A comprehensive review of the development of zero waste management: lessons learned and guidelines. J. Clean. Prod. 91 , 12-25.

3. Korhonen J, Nuur C, Feldmann A, Birkie SE (2018) Circular economy as an essentially contested concept. J Clean Prod 175:544-552.

4. Xu Y, Zhang L, Yeh CH, Liu Y (2018) Evaluating E-WASTE recycling innovation strategies with interacting sustainability-related criteria. J Clean Prod 190:618-629.

5. Cole, C., Osmania, M., Quddusa, M., Wheatleya, A., Kay, K., 2014. Towards a zero waste strategy for an English local authority. Resour. Conserv. Recycl. 89, 64-75.

6. Moh, Y. (2017). Solid waste management transformation and future challenges of source separation and recycling practice in Malaysia. Resources, Conservation and Recycling, 116, 1-14.

7. United Nations (2014). World urbanization prospects: The 2014 Revision, Highlights (ST/ESA/SER.A/352). New York. United States of Americahttps://doi.org/10.4054/DemRes.2005.12.9.

8. Himabindu, P., Udayashankara, T. H., \& Madhukar, M. A. (2015). Critical review on biomedical waste and effect of mismanagement. Int J Eng Res Technol, 4(03), 2278-0181.

9. WebsiteShareE-WasteStatistics.IISD.2019.Accessat:https://sdg.iisd.org/news/website-shares-e-waste-statistics/.

10. Aljerf, L., 2018. Data of thematic analysis of farmer's use behavior of recycled industrial wastewater. Data in Brief 21, $240 \mathrm{e} 250$. 
11. Calzada, I. (2018). (Smart) citizens from data providers to decision-makers? The case study of Barcelona. Sustainability, $10(9), 3252$.

12. March, H., \& Ribera-Fumaz, R. (2016). Smart contradictions: The politics of making Barcelona a Self-sufficient city. European Urban and Regional Studies, 23(4), 816-830.

13. Yigitcanlar, T., Kankanamge, N., \& Vella, K. (2020). How Are Smart City Concepts and Technologies Perceived and Utilized? A Systematic GeoTwitter Analysis of Smart Cities in Australia. Journal of Urban Technology, 1-20.

14. Omar, M. F., Termizi, A. A. A., Zainal, D., Wahap, N. A., Ismail, N. M., \& Ahmad, N. (2016, June). Implementation of spatial smart waste management system in Malaysia. In IOP Conference Series: Earth and Environmental Science (Vol. 37, No. 1, p. 012059). IOP Publishing.

15. Mingaleva, Z., Vukovic, N., Volkova, I., \& Salimova, T. (2020). Waste management in green and smart cities: A case study of Russia. Sustainability, 12(1), 94.

16. Yigitcanlar, T., Kamruzzaman, M., Foth, M., Sabatini-Marques, J., da Costa, E., \& Ioppolo, G. (2019). Can cities become smart without being sustainable? A systematic review of the literature. Sustainable cities and society, 45, 348-365.

17. Sharma, M., Joshi, S., Kannan, D., Govindan, K., Singh, R., \& Purohit, H. C. (2020). Internet of Things (IoT) adoption barriers of smart cities' waste management: An Indian context. Journal of Cleaner Production, 122047.

18. Kerdlap, P., Low, J. S. C., \& Ramakrishna, S. (2019). Zero waste manufacturing: A framework and review of technology, research, and implementation barriers for enabling a circular economy transition in Singapore. Resources, Conservation and Recycling, $151,104438$.

19. Bui, T. D., Tsai, F. M., Tseng, M. L., \& Ali, M. H. (2020). Identifying sustainable solid waste management barriers in practice using the fuzzy Delphi method. Resources, Conservation and Recycling, 154, 104625. 
20. Rana, N. P., Luthra, S., Mangla, S. K., Islam, R., Roderick, S., \& Dwivedi, Y. K. (2019). Barriers to the development of smart cities in Indian context. Information Systems Frontiers, 21(3), 503-525.

21. Addae, B. A., Zhang, L., Zhou, P., \& Wang, F. (2019). Analyzing barriers of Smart Energy City in Accra with two-step fuzzy DEMATEL. Cities, 89, $218-227$.

22. Farooque, M., Zhang, A., \& Liu, Y. (2019). Barriers to circular food supply chains in China. Supply Chain Management: An International Journal.

23. Zhang, B., Lai, K. H., Wang, B., \& Wang, Z. (2019). From intention to action: How do personal attitudes, facilities accessibility, and government stimulus matter for household waste sorting?. Journal of environmental management, 233, 447-458.

24. Guerrero, L. A., Maas, G., \& Hogland, W. (2013). Solid waste management challenges for cities in developing countries. Waste management, 33(1), $220-232$.

25. Rao, P. V., Azeez, P. M. A., Peri, S. S., Kumar, V., Devi, R. S., Rengarajan, A., ... \& Praveenkumar, P. (2020, January). IoT based Waste Management for Smart Cities. In 2020 International Conference on Computer Communication and Informatics (ICCCI) (pp. 1-5). IEEE.

26. Doron, Assa \& JEFFREY, ROBIN. (2018). Waste of a Nation: Garbage and Growth in India. 10.2307/j.ctv2867m8.

27. Shah, P. J., Anagnostopoulos, T., Zaslavsky, A., \& Behdad, S. (2018). A stochastic optimization framework for planning of waste collection and value recovery operations in smart and sustainable cities. Waste management, 78, 104-114.

28. Esmaeilian, B., Wang, B., Lewis, K., Duarte, F., Ratti, C., \& Behdad, S. (2018). The future of waste management in smart and sustainable cities: A review and concept paper. Waste management, 81, 177-195.

29. Das, S., Lee, S. H., Kumar, P., Kim, K. H., Lee, S. S., \& Bhattacharya, S. S. (2019). Solid waste management: Scope and the challenge of sustainability. Journal of cleaner production, 228, 658-678. 
30. Zorpas, A. A. (2020). Strategy development in the framework of waste management. Science of The Total Environment, $716,137088$.

31. Kala, K., \& Bolia, N. B. (2020). Waste Management Communication Policy for Effective Citizen Awareness. Journal of Policy Modeling.

32. Bui, T. D., Tsai, F. M., Tseng, M. L., \& Ali, M. H. (2020). Identifying sustainable solid waste management barriers in practice using the fuzzy Delphi method. Resources, Conservation and Recycling, 154, 104625.

33. Fatimah, Y. A., Govindan, K., Murniningsih, R., \& Setiawan, A. (2020). A sustainable circular economy approach for smart waste management system to achieve sustainable development goals: Case study in Indonesia. Journal of Cleaner Production, 122263.

34. Hue, C. (2020). Digitalization of waste management processes in smart cities or regions (Doctoral dissertation).

35. Vanapalli, K. R., Sharma, H. B., Ranjan, V. P., Samal, B., Bhattacharya, J., Dubey, B. K., \& Goel, S. (2020). Challenges and strategies for effective plastic waste management during and post COVID-19 pandemic. Science of The Total Environment, 750, 141514.

36. Zsigraiova, Z., Semiao, V., Beijoco, F., 2013. Operation costs and pollutant emissions reduction by definition of new collection scheduling and optimization of MSW collection routes using GIS. The case study of Barreiro, Portugal. Waste Manage. 33 (4), $793-806$.

37. Hannan, M. A., Al Mamun, M. A., Hussain, A., Basri, H., \& Begum, R. A. (2015). A review on technologies and their usage in solid waste monitoring and management systems: Issues and challenges. Waste Management, 43, 509-523.

38. Zurbrügg, C., Gfrerer, M., Ashadi, H., Brenner, W., \& Küper, D. (2012). Determinants of sustainability in solid waste management-The Gianyar Waste Recovery Project in Indonesia. Waste management, 32(11), 2126-2133.

39. Aslam, M. S., Huang, B., \& Cui, L. (2020). Review of construction and demolition waste management in China and USA. Journal of Environmental Management, 264, 110445.

40. SBallal, V., Patil, S. S., \& Dange, N. P. (2019). Smart City Waste Management System using IoT SERVER. management, 6(04). 
41. Christ, O., Czarniecki, M., Kressig, C., \& Scherer, L. (2017). Satisfaction benchmark for smart cities. In Happy City-How to Plan and Create the Best Livable Area for the People (pp. 71-102). Springer, Cham.

42. Shmelev, S. E., \& Shmeleva, I. A. (2019). Multidimensional sustainability benchmarking for smart megacities. Cities, 92, $134-163$.

43. Samarakkody, A. L., Bandara, H. D., \& Kulatunga, U. A Systematic Review of Performance Measurement Models for Smart Cities.

44. Moustaka, V., Maitis, A., Vakali, A., \& Anthopoulos, L. G. (2020, April). CityDNA Dynamics: A Model for Smart City Maturity and Performance Benchmarking. In Companion Proceedings of the Web Conference 2020 (pp. 829-833).

45. Banerjee, S., \& Sarkhel, P. (2020). Municipal solid waste management, household and local government participation: a cross country analysis. Journal of Environmental Planning and Management, 63(2), 210-235.

46. Vasava, H. K., \& Sheth, L. (2019). Integrated Waste Management of Smart City Gandhinagar.

47. Nancy, G. P., \& Resmi, R. (2019). Smart City Platform Development for Waste Management.

48. Masood, A., \& Ahmad, K. (2020). Assessment of Municipal Solid Waste Management in Jammu City: Problems, Prospects and Solutions. In Smart Cities-Opportunities and Challenges (pp. 257-275). Springer, Singapore.

49. Chatterjee, S., \& Kar, A. K. (2018). Regulation and governance of the internet of things in India. Digital Policy, Regulation and Governance.

50. Tsai, W. T. (2020). Turning Food Waste into Value-Added Resources: Current Status and Regulatory Promotion in Taiwan. Resources, 9(5), 53.

51. Shaukat, N., Ullah, Z., Khan, B., Ali, S. M., \& Waseem, A. (2019, July). An Information-Based Waste Management Approach for Pakistan. In 2019 International Conference on Electrical, Communication, and Computer Engineering (ICECCE) (pp. 1-5). IEEE.

52. Lam, P. T., \& Yang, W. (2020). Factors influencing the consideration of Public-Private Partnerships (PPP) for smart city projects: Evidence from Hong

Kong. Cities, 99, 102606. 
53. Dolla, T., \& Laishram, B. (2020). Factors affecting public-private partnership preference in Indian municipal waste sector. International Journal of Construction Management, 20(6), 567-584.

54. Mangla, S. K., Kumar, P., \& Barua, M. K. (2015). Risk analysis in green supply chain using fuzzy AHP approach: a case study. Resources, Conservation and Recycling, 104, 375-390.

55. Govindan, K., Mangla, S.K., \& Luthra, S. (2017) Prioritising indicators in improving supply chain performance using fuzzy AHP: insights from the case example of four Indian manufacturing companies, Production Planning \& Control, 28, (6-8), 552-573, DOI: 10.1080/09537287.2017.1309716.

56. Mangla, S. K., Luthra, S., Jakhar, S. K., Tyagi, M., \& Narkhede, B. E. (2018). Benchmarking the logistics management implementation using Delphi and fuzzy DEMATEL. Benchmarking: An International Journal.

57. Ehsani, E., Kazemi, N., Olugu, E. U., Grosse, E. H., \& Schwindl, K. (2016). Applying fuzzy multi- objective linear programming to a project management decision with nonlinear fuzzy membership functions. Neural Computing and Applications, 1-14.

58. Farooque, M., Jain, V., Zhang, A., \& Li, Z. (2020). Fuzzy DEMATEL analysis of barriers to Blockchain-based life cycle assessment in China. Computers \& Industrial Engineering, 147, 106684.

59. Wu, W. W., \& Lee, Y. T. (2007). Developing global managers' competencies using the fuzzy DEMATEL method. Expert systems with applications, 32(2), 499-507.

60. Opricovic, S., \& Tzeng, G. H. (2003). Defuzzification within a multicriteria decision model. International Journal of Uncertainty, Fuzziness and Knowledge-Based Systems, 11(05), 635-652.

61. Muduli, K., \& Barve, A. (2012, April). Challenges to waste management practices in Indian health care sector. In International Conference on Environment Science and Engineering. IPCBEE, IACSIT Press, Singapore (Vol. 32). 
62. Priyadarshini, P., \& Abhilash, P. C. (2020). Circular economy practices within energy and waste management sectors of India: A meta-analysis.

Bioresource Technology, 304, 123018.

63. Mandal, K. (2019). Review on evolution of municipal solid waste management in India: practices, challenges and policy implications. Journal of Material Cycles and Waste Management, 1-17.

64. Guidelines for SWACHH BHARAT MISSION GRAMIN. October 2017. Access at: http://swachhbharatmission.gov.in/sbmcms/writereaddata/images/pdf/Guidelines/Complete-set-guidelines.pdf.

65. Afroz, R., Hanaki, K., \& Tudin, R. (2011). Factors affecting waste generation: a study in a waste management program in Dhaka City, Bangladesh. Environmental monitoring and assessment, 179(1-4), 509-519.

66. National waste management benchmarking, (2011). Available from: http://www.nationalbenchmarking.ca/public/docs/nswbi_proposal_nov10.pdf.

67. Greene, Liz. “China's Recycling Ban: What Do We Do with Our Plastics Now?” Earth911.Com, Earth911, 8 Apr. 2018, https://earth911.com/businesspolicy/china-ban-plastics/.

68. Luczak, E. (2020). The Effects of China's National Sword Policy on the United States Recycling System and What the United States can do with the Buildup of Recycling in the Recycling Centers (Doctoral dissertation).

69. Leal Filho, W., Brandli, L., Moora, H., Kruopienè, J., \& Stenmarck, Å. (2016). Benchmarking approaches and methods in the field of urban waste management. Journal of Cleaner Production, 112, 4377-4386.

70. Ahluwalia, I. J., \& Patel, U. (2018). Solid waste management in india: an assessment of resource recovery and environmental impact. 


\section{Appendix}

Table 2: Municipal Solid Waste Composition

\begin{tabular}{|c|c|c|}
\hline Type of MSW & Composition of waste & Sources \\
\hline Biodegradable waste or organic waste & Paper, wood, kitchen waste, animal waste, rubber, yard waste, food & $\begin{array}{l}\text { Household, Food processing } \\
\text { industries, Organic farms }\end{array}$ \\
\hline Recyclable waste & Plastic, Metals, Aluminium foils, Tins, Paper and cupboard, Bottles & $\begin{array}{l}\text { Shops, Automobile industries, } \\
\text { scraps yards }\end{array}$ \\
\hline Hazardous waste & $\begin{array}{l}\text { Paints, electronic waste, aerosol spray cans, light tubes, fluorescent lamps, } \\
\text { chemicals, tyres }\end{array}$ & $\begin{array}{l}\text { Paint industries, Household, } \\
\text { Chemical industries }\end{array}$ \\
\hline Toxic waste & Pesticides, herbicides, fungicides & $\begin{array}{l}\text { Chemical industries, various } \\
\text { pesticides and herbicides } \\
\text { manufacturing industries }\end{array}$ \\
\hline Inert waste & Construction waste, debris, rocks and sand & $\begin{array}{l}\text { Construction sites, building } \\
\text { demolishing sites }\end{array}$ \\
\hline
\end{tabular}




\section{Government Project Perspective Result}

\section{Table I. Direct Relation Matrix}

\begin{tabular}{|c|c|c|c|c|c|c|c|c|c|c|}
\hline & H1 & H2 & H3 & H4 & H5 & H6 & H7 & H8 & H9 & H10 \\
\hline H1 & $(0.000,0.000,0.000)$ & $(0.250,0.500,0.750)$ & $(0.250,0.500,0.750)$ & $(0.083,0.250,0.500)$ & $(0.250,0.500,0.750)$ & $(0.250,0.500,0.750)$ & $(0.500,0.750,0.917)$ & $(0.333,0.583,0.750)$ & $(0.167,0.417,0.667)$ & $(0.250,0.500,0.750)$ \\
\hline H2 & $(0.250,0.500,0.750)$ & $(0.000,0.000,0.000)$ & $(0.083,0.250,0.500)$ & $(0.500,0.750,1.000)$ & $(0.083,0.167,0.417)$ & $(0.250,0.500,0.667)$ & $(0.083,0.333,0.583)$ & $(0.333,0.583,0.833)$ & $(0.500,0.750,0.917)$ & $(0.417,0.667,0.917)$ \\
\hline H3 & $(0.333,0.583,0.833)$ & $(0.083,0.333,0.583)$ & $(0.000,0.000,0.000)$ & $(0.000,0.167,0.417)$ & $(0.500,0.750,0.917)$ & $(0.500,0.750,0.917)$ & $(0.417,0.667,0.833)$ & $(0.417,0.667,0.833)$ & $(0.333,0.583,0.833)$ & $(0.167,0.417,0.667)$ \\
\hline H4 & $(0.167,0.333,0.583)$ & $(0.500,0.750,0.917)$ & $(0.167,0.417,0.667)$ & $(0.000,0.000,0.000)$ & $(0.083,0.167,0.417)$ & $(0.000,0.167,0.417)$ & $(0.083,0.333,0.583)$ & $(0.500,0.750,1.000)$ & $(0.167,0.417,0.667)$ & $(0.250,0.500,0.750)$ \\
\hline H5 & $(0.250,0.500,0.667)$ & $(0.083,0.167,0.417)$ & $(0.167,0.417,0.667)$ & $(0.083,0.333,0.583)$ & $(0.000,0.000,0.000)$ & $(0.250,0.417,0.667)$ & $(0.250,0.500,0.667)$ & $(0.417,0.667,0.833)$ & $(0.167,0.417,0.667)$ & $(0.417,0.667,0.917)$ \\
\hline H6 & $(0.417,0.667,0.917)$ & $(0.167,0.417,0.667)$ & $(0.667,0.917,1.000)$ & $(0.000,0.250,0.500)$ & $(0.250,0.500,0.750)$ & $(0.000,0.000,0.000)$ & $(0.167,0.417,0.667)$ & $(0.167,0.417,0.667)$ & $(0.333,0.500,0.750)$ & $(0.333,0.583,0.750)$ \\
\hline H7 & $(0.417,0.667,0.917)$ & $(0.500,0.750,0.917)$ & $(0.333,0.583,0.833)$ & $(0.250,0.500,0.750)$ & $(0.500,0.750,0.833)$ & $(0.250,0.417,0.583)$ & $(0.000,0.000,0.000)$ & $(0.083,0.250,0.500)$ & $(0.333,0.583,0.750)$ & $(0.250,0.500,0.750)$ \\
\hline H8 & $(0.167,0.333,0.583)$ & $(0.500,0.750,1.000)$ & $(0.333,0.583,0.833)$ & $(0.500,0.750,1.000)$ & $(0.167,0.417,0.667)$ & $(0.000,0.167,0.417)$ & $(0.000,0.250,0.500)$ & $(0.000,0.000,0.000)$ & $(0.417,0.667,0.833)$ & $(0.250,0.500,0.750)$ \\
\hline H9 & $(0.167,0.417,0.667)$ & $(0.417,0.667,0.833)$ & $(0.333,0.583,0.833)$ & $(0.417,0.667,0.917)$ & $(0.333,0.583,0.833)$ & $(0.250,0.500,0.750)$ & $(0.250,0.500,0.750)$ & $(0.417,0.667,0.833)$ & $(0.000,0.000,0.000)$ & $(0.500,0.750,1.000)$ \\
\hline H10 & $(0.167,0.417,0.667)$ & $(0.333,0.583,0.750)$ & $(0.250,0.500,0.750)$ & $(0.250,0.500,0.750)$ & $(0.250,0.417,0.667)$ & $(0.333,0.500,0.667)$ & $(0.333,0.583,0.833)$ & $(0.333,0.583,0.833)$ & $(0.167,0.333,0.583)$ & $(0.000,0.000,0.000)$ \\
\hline
\end{tabular}

\section{Table II. Normalised fuzzy Direct Relation Matrix}

\begin{tabular}{|c|c|c|c|c|c|c|c|c|c|c|}
\hline & H1 & H2 & H3 & H4 & H5 & H6 & H7 & H8 & H9 & H10 \\
\hline H1 & $(0.000,0.000,0.000)$ & $(0.034,0.067,0.101)$ & $(0.034,0.067,0.101)$ & $(0.011,0.034,0.067)$ & $(0.034,0.067,0.101)$ & $(0.034,0.067,0.101)$ & $(0.067,0.101,0.124)$ & $(0.045,0.079,0.101)$ & $(0.023,0.056,0.090)$ & $(0.034,0.067,0.101)$ \\
\hline H2 & $(0.034,0.067,0.101)$ & $(0.000,0.000,0.000)$ & $(0.011,0.034,0.067)$ & $(0.067,0.101,0.135)$ & $(0.011,0.023,0.056)$ & $(0.034,0.067,0.090)$ & $(0.011,0.045,0.079)$ & $(0.045,0.079,0.112)$ & $(0.067,0.101,0.124)$ & $(0.056,0.090,0.124)$ \\
\hline H3 & $(0.045,0.079,0.112)$ & $(0.011,0.045,0.079)$ & $(0.000,0.000,0.000)$ & $(0.000,0.023,0.056)$ & $(0.067,0.101,0.124)$ & $(0.067,0.101,0.124)$ & $(0.056,0.090,0.112)$ & $(0.056,0.090,0.112)$ & $(0.045,0.079,0.112)$ & $(0.023,0.056,0.090)$ \\
\hline
\end{tabular}




\begin{tabular}{|c|c|c|c|c|c|c|c|c|c|c|}
\hline H4 & $(0.023,0.045,0.079)$ & $(0.067,0.101,0.124)$ & $(0.023,0.056,0.090)$ & $(0.000,0.000,0.000)$ & $(0.011,0.023,0.056)$ & $(0.000,0.023,0.056)$ & $(0.011,0.045,0.079)$ & $(0.067,0.101,0.135)$ & $(0.023,0.056,0.090)$ & $(0.034,0.067,0.101)$ \\
\hline H5 & $(0.034,0.067,0.090)$ & $(0.011,0.023,0.056)$ & $(0.023,0.056,0.090)$ & $(0.011,0.045,0.079)$ & $(0.000,0.000,0.000)$ & $(0.034,0.056,0.090)$ & $(0.034,0.067,0.090)$ & $(0.056,0.090,0.112)$ & $(0.023,0.056,0.090)$ & $(0.056,0.090,0.124)$ \\
\hline H6 & $(0.056,0.090,0.124)$ & $(0.023,0.056,0.090)$ & $(0.090,0.124,0.135)$ & $(0.000,0.034,0.067)$ & $(0.034,0.067,0.101)$ & $(0.000,0.000,0.000)$ & $(0.023,0.056,0.090)$ & $(0.023,0.056,0.090)$ & $(0.045,0.067,0.101)$ & $(0.045,0.079,0.101)$ \\
\hline H7 & $(0.056,0.090,0.124)$ & $(0.067,0.101,0.124)$ & $(0.045,0.079,0.112)$ & $(0.034,0.067,0.101)$ & $(0.067,0.101,0.112)$ & $(0.034,0.056,0.079)$ & $(0.000,0.000,0.000)$ & $(0.011,0.034,0.067)$ & $(0.045,0.079,0.101)$ & $(0.034,0.067,0.101)$ \\
\hline H8 & $(0.023,0.045,0.079)$ & $(0.067,0.101,0.135)$ & $(0.045,0.079,0.112)$ & $(0.067,0.101,0.135)$ & $(0.023,0.056,0.090)$ & $(0.000,0.023,0.056)$ & $(0.000,0.034,0.067)$ & $(0.000,0.000,0.000)$ & $(0.056,0.090,0.112)$ & $(0.034,0.067,0.101)$ \\
\hline H9 & $(0.023,0.056,0.090)$ & $(0.056,0.090,0.112)$ & $(0.045,0.079,0.112)$ & $(0.056,0.090,0.124)$ & $(0.045,0.079,0.112)$ & $(0.034,0.067,0.101)$ & $(0.034,0.067,0.101)$ & $(0.056,0.090,0.112)$ & $(0.000,0.000,0.000)$ & $(0.067,0.101,0.135)$ \\
\hline H10 & $(0.023,0.056,0.090)$ & $(0.045,0.079,0.101)$ & $(0.034,0.067,0.101)$ & $(0.034,0.067,0.101)$ & $(0.034,0.056,0.090)$ & $(0.045,0.067,0.090)$ & $(0.045,0.079,0.112)$ & $(0.045,0.079,0.112)$ & $(0.023,0.045,0.079)$ & $(0.000,0.000,0.000)$ \\
\hline
\end{tabular}

\section{Table III. Fuzzy Total-Relation Matrix}

\begin{tabular}{|c|c|c|c|c|c|c|c|c|c|c|}
\hline & H1 & H2 & H3 & H4 & H5 & H6 & H7 & H8 & H9 & H10 \\
\hline H1 & $(0.017,0.099,0.734)$ & $(0.052,0.173,0.856)$ & $(0.051,0.169,0.851)$ & $(0.026,0.128,0.788)$ & $(0.050,0.160,0.794)$ & $(0.048,0.152,0.752)$ & $(0.079,0.190,0.822)$ & $(0.062,0.186,0.879)$ & $(0.041,0.159,0.828)$ & $(0.052,0.176,0.895)$ \\
\hline H2 & $(0.048,0.158,0.822)$ & $(0.023,0.113,0.766)$ & $(0.030,0.138,0.822)$ & $(0.082,0.190,0.846)$ & $(0.027,0.115,0.752)$ & $(0.046,0.149,0.739)$ & $(0.025,0.138,0.782)$ & $(0.066,0.188,0.890)$ & $(0.082,0.196,0.854)$ & $(0.075,0.195,0.913)$ \\
\hline H3 & $(0.063,0.181,0.862)$ & $(0.033,0.161,0.863)$ & $(0.023,0.117,0.788)$ & $(0.017,0.125,0.803)$ & $(0.085,0.200,0.839)$ & $(0.082,0.190,0.795)$ & $(0.071,0.189,0.838)$ & $(0.076,0.206,0.916)$ & $(0.064,0.187,0.873)$ & $(0.045,0.176,0.915)$ \\
\hline H4 & $(0.034,0.125,0.744)$ & $(0.082,0.190,0.815)$ & $(0.034,0.141,0.778)$ & $(0.016,0.086,0.669)$ & $(0.023,0.102,0.696)$ & $(0.011,0.097,0.658)$ & $(0.021,0.124,0.724)$ & $(0.082,0.191,0.845)$ & $(0.038,0.145,0.768)$ & $(0.049,0.159,0.830)$ \\
\hline H5 & $(0.047,0.152,0.763)$ & $(0.029,0.124,0.765)$ & $(0.039,0.150,0.789)$ & $(0.025,0.129,0.745)$ & $(0.015,0.088,0.652)$ & $(0.045,0.133,0.695)$ & $(0.046,0.152,0.743)$ & $(0.071,0.186,0.833)$ & $(0.038,0.147,0.774)$ & $(0.071,0.185,0.856)$ \\
\hline H6 & $(0.072,0.186,0.854)$ & $(0.040,0.164,0.855)$ & $(0.105,0.222,0.889)$ & $(0.014,0.128,0.795)$ & $(0.053,0.165,0.804)$ & $(0.019,0.095,0.670)$ & $(0.041,0.157,0.804)$ & $(0.045,0.172,0.881)$ & $(0.062,0.171,0.847)$ & $(0.063,0.189,0.905)$ \\
\hline H7 & $(0.074,0.191,0.867)$ & $(0.086,0.211,0.898)$ & $(0.063,0.186,0.883)$ & $(0.050,0.166,0.838)$ & $(0.084,0.197,0.824)$ & $(0.052,0.152,0.754)$ & $(0.019,0.108,0.734)$ & $(0.038,0.160,0.878)$ & $(0.065,0.187,0.860)$ & $(0.057,0.188,0.921)$ \\
\hline H8 & $(0.036,0.136,0.801)$ & $(0.084,0.201,0.882)$ & $(0.058,0.172,0.855)$ & $(0.082,0.188,0.844)$ & $(0.036,0.142,0.778)$ & $(0.014,0.109,0.710)$ & $(0.014,0.126,0.771)$ & $(0.023,0.115,0.788)$ & $(0.072,0.185,0.844)$ & $(0.052,0.173,0.893)$ \\
\hline H9 & $(0.042,0.166,0.895)$ & $(0.079,0.211,0.949)$ & $(0.065,0.194,0.943)$ & $(0.074,0.195,0.915)$ & $(0.063,0.182,0.878)$ & $(0.051,0.165,0.823)$ & $(0.050,0.174,0.880)$ & $(0.081,0.217,0.977)$ & $(0.023,0.121,0.827)$ & $(0.089,0.223,1.011)$ \\
\hline H10 & $(0.039,0.149,0.805)$ & $(0.063,0.181,0.845)$ & $(0.051,0.165,0.839)$ & $(0.048,0.156,0.806)$ & $(0.049,0.145,0.773)$ & $(0.058,0.149,0.731)$ & $(0.057,0.167,0.801)$ & $(0.064,0.184,0.878)$ & $(0.041,0.146,0.807)$ & $(0.020,0.109,0.791)$ \\
\hline
\end{tabular}


Table IV. The Crisp Total-relation Matrix

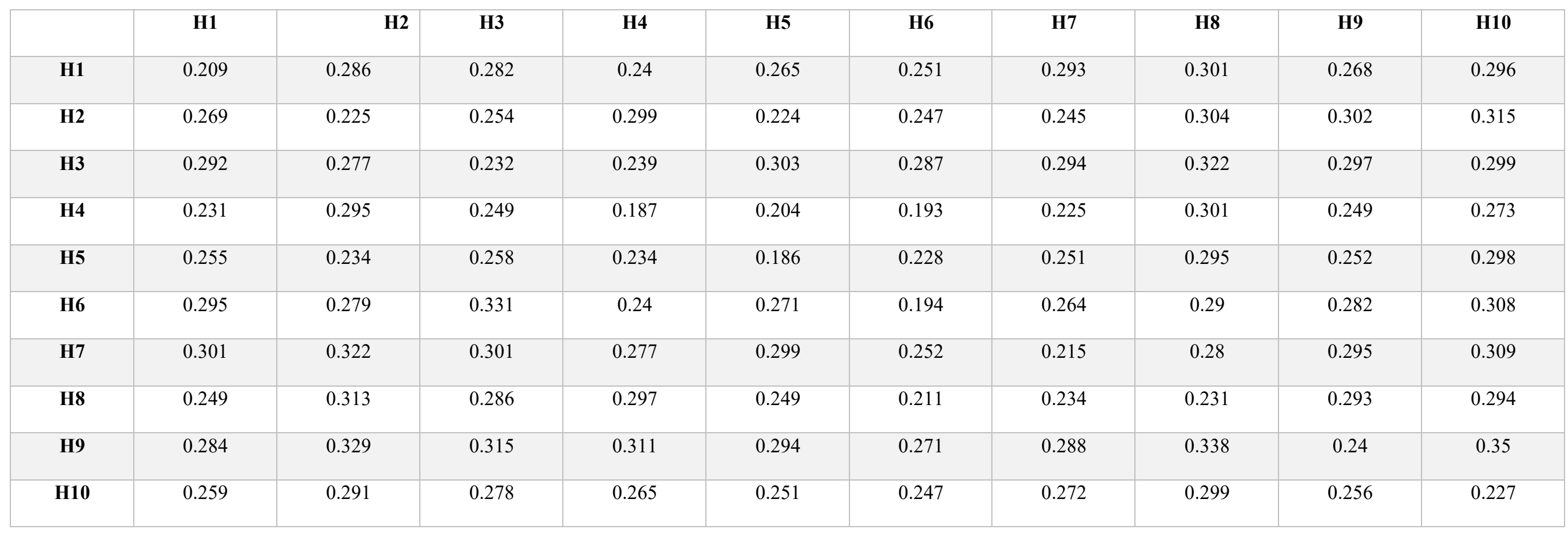




\section{Technology Contributor's Perspective}

\section{Table (i). The Direct-Relation Matrix}

\begin{tabular}{|c|c|c|c|c|c|c|c|c|c|c|}
\hline & H1 & H2 & H3 & H4 & H5 & H6 & H7 & H8 & H9 & H10 \\
\hline H1 & $(0.000,0.000,0.000)$ & $(0.500,0.750,0.833)$ & $(0.333,0.583,0.833)$ & $(0.000,0.167,0.417)$ & $(0.250,0.417,0.667)$ & $(0.333,0.500,0.667)$ & $(0.167,0.250,0.500)$ & $(0.750,1.000,1.000)$ & $(0.583,0.833,1.000)$ & $(0.500,0.750,0.917)$ \\
\hline H2 & $(0.583,0.833,1.000)$ & $(0.000,0.000,0.000)$ & $(0.500,0.750,0.917)$ & $(0.333,0.583,0.750)$ & $(0.167,0.417,0.667)$ & $(0.250,0.500,0.750)$ & $(0.500,0.750,0.917)$ & $(0.750,1.000,1.000)$ & $(0.667,0.917,1.000)$ & $(0.333,0.583,0.750)$ \\
\hline H3 & $(0.167,0.417,0.667)$ & $(0.500,0.750,0.917)$ & $(0.000,0.000,0.000)$ & $(0.333,0.583,0.833)$ & $(0.250,0.417,0.583)$ & $(0.750,1.000,1.000)$ & $(0.500,0.750,0.917)$ & $(0.500,0.750,0.917)$ & $(0.750,1.000,1.000)$ & $(0.500,0.750,0.917)$ \\
\hline H4 & $(0.417,0.667,0.833)$ & $(0.583,0.833,1.000)$ & $(0.417,0.667,0.833)$ & $(0.000,0.000,0.000)$ & $(0.250,0.500,0.667)$ & $(0.083,0.250,0.500)$ & $(0.167,0.417,0.667)$ & $(0.583,0.833,0.917)$ & $(0.500,0.750,0.917)$ & $(0.333,0.583,0.833)$ \\
\hline H5 & $(0.167,0.417,0.667)$ & $(0.250,0.500,0.750)$ & $(0.500,0.750,1.000)$ & $(0.500,0.750,0.833)$ & $(0.000,0.000,0.000)$ & $(0.583,0.833,1.000)$ & $(0.500,0.750,0.917)$ & $(0.417,0.667,0.917)$ & $(0.333,0.583,0.750)$ & $(0.333,0.583,0.833)$ \\
\hline H6 & $(0.333,0.583,0.750)$ & $(0.417,0.667,0.833)$ & $(0.750,1.000,1.000)$ & $(0.417,0.667,0.833)$ & $(0.583,0.833,0.917)$ & $(0.000,0.000,0.000)$ & $(0.250,0.500,0.750)$ & $(0.500,0.750,0.917)$ & $(0.583,0.833,0.917)$ & $(0.500,0.750,0.917)$ \\
\hline H7 & $(0.500,0.750,0.917)$ & $(0.417,0.667,0.917)$ & $(0.583,0.833,1.000)$ & $(0.250,0.500,0.750)$ & $(0.583,0.833,0.917)$ & $(0.417,0.667,0.917)$ & $(0.000,0.000,0.000)$ & $(0.167,0.417,0.667)$ & $(0.333,0.583,0.833)$ & $(0.417,0.667,0.917)$ \\
\hline H8 & $(0.667,0.917,1.000)$ & $(0.583,0.833,1.000)$ & $(0.333,0.583,0.833)$ & $(0.333,0.583,0.750)$ & $(0.500,0.750,1.000)$ & $(0.167,0.417,0.667)$ & $(0.417,0.667,0.833)$ & $(0.000,0.000,0.000)$ & $(0.417,0.667,0.833)$ & $(0.333,0.583,0.833)$ \\
\hline H9 & $(0.583,0.833,0.917)$ & $(0.583,0.833,0.917)$ & $(0.500,0.750,0.833)$ & $(0.750,1.000,1.000)$ & $(0.500,0.750,0.917)$ & $(0.333,0.583,0.750)$ & $(0.583,0.833,1.000)$ & $(0.583,0.833,1.000)$ & $(0.000,0.000,0.000)$ & $(0.667,0.917,1.000)$ \\
\hline H10 & $(0.500,0.750,0.917)$ & $(0.250,0.500,0.750)$ & $(0.333,0.583,0.833)$ & $(0.500,0.750,0.917)$ & $(0.417,0.667,0.833)$ & $(0.167,0.417,0.667)$ & $(0.167,0.333,0.583)$ & $(0.500,0.750,0.917)$ & $(0.583,0.833,1.000)$ & $(0.000,0.000,0.000)$ \\
\hline
\end{tabular}

Table(ii). The normalized fuzzy direct-relation matrix

\begin{tabular}{|c|c|c|c|c|c|c|c|c|c|c|}
\hline & H1 & H2 & H3 & H4 & H5 & H6 & H7 & H8 & H9 & H10 \\
\hline H1 & $(0.000,0.000,0.000)$ & $(0.060,0.090,0.100)$ & $(0.040,0.070,0.100)$ & $(0.000,0.020,0.050)$ & $(0.030,0.050,0.080)$ & $(0.040,0.060,0.080)$ & $(0.020,0.030,0.060)$ & $(0.090,0.120,0.120)$ & $(0.070,0.100,0.120)$ & $(0.060,0.090,0.110)$ \\
\hline H2 & $(0.070,0.100,0.120)$ & $(0.000,0.000,0.000)$ & $(0.060,0.090,0.110)$ & $(0.040,0.070,0.090)$ & $(0.020,0.050,0.080)$ & $(0.030,0.060,0.090)$ & $(0.060,0.090,0.110)$ & $(0.090,0.120,0.120)$ & $(0.080,0.110,0.120)$ & $(0.040,0.070,0.090)$ \\
\hline H3 & $(0.020,0.050,0.080)$ & $(0.060,0.090,0.110)$ & $(0.000,0.000,0.000)$ & $(0.040,0.070,0.100)$ & $(0.030,0.050,0.070)$ & $(0.090,0.120,0.120)$ & $(0.060,0.090,0.110)$ & $(0.060,0.090,0.110)$ & $(0.090,0.120,0.120)$ & $(0.060,0.090,0.110)$ \\
\hline H4 & $(0.050,0.080,0.100)$ & $(0.070,0.100,0.120)$ & $(0.050,0.080,0.100)$ & $(0.000,0.000,0.000)$ & $(0.030,0.060,0.080)$ & $(0.010,0.030,0.060)$ & $(0.020,0.050,0.080)$ & $(0.070,0.100,0.110)$ & $(0.060,0.090,0.110)$ & $(0.040,0.070,0.100)$ \\
\hline H5 & $(0.020,0.050,0.080)$ & $(0.030,0.060,0.090)$ & $(0.060,0.090,0.120)$ & $(0.060,0.090,0.100)$ & $(0.000,0.000,0.000)$ & $(0.070,0.100,0.120)$ & $(0.060,0.090,0.110)$ & $(0.050,0.080,0.110)$ & $(0.040,0.070,0.090)$ & $(0.040,0.070,0.100)$ \\
\hline H6 & $(0.040,0.070,0.090)$ & $(0.050,0.080,0.100)$ & $(0.090,0.120,0.120)$ & $(0.050,0.080,0.100)$ & $(0.070,0.100,0.110)$ & $(0.000,0.000,0.000)$ & $(0.030,0.060,0.090)$ & $(0.060,0.090,0.110)$ & $(0.070,0.100,0.110)$ & $(0.060,0.090,0.110)$ \\
\hline H7 & $(0.060,0.090,0.110)$ & $(0.050,0.080,0.110)$ & $(0.070,0.100,0.120)$ & $(0.030,0.060,0.090)$ & $(0.070,0.100,0.110)$ & $(0.050,0.080,0.110)$ & $(0.000,0.000,0.000)$ & $(0.020,0.050,0.080)$ & $(0.040,0.070,0.100)$ & $(0.050,0.080,0.110)$ \\
\hline
\end{tabular}




\begin{tabular}{|c|c|c|c|c|c|c|c|c|c|c|}
\hline H8 & $(0.080,0.110,0.120)$ & $(0.070,0.100,0.120)$ & $(0.040,0.070,0.100)$ & $(0.040,0.070,0.090)$ & $(0.060,0.090,0.120)$ & $(0.020,0.050,0.080)$ & $(0.050,0.080,0.100)$ & $(0.000,0.000,0.000)$ & $(0.050,0.080,0.100)$ & $(0.040,0.070,0.100)$ \\
\hline H9 & $(0.070,0.100,0.110)$ & $(0.070,0.100,0.110)$ & $(0.060,0.090,0.100)$ & $(0.090,0.120,0.120)$ & $(0.060,0.090,0.110)$ & $(0.040,0.070,0.090)$ & $(0.070,0.100,0.120)$ & $(0.070,0.100,0.120)$ & $(0.000,0.000,0.000)$ & $(0.080,0.110,0.120)$ \\
\hline H10 & $(0.060,0.090,0.110)$ & $(0.030,0.060,0.090)$ & $(0.040,0.070,0.100)$ & $(0.060,0.090,0.110)$ & $(0.050,0.080,0.100)$ & $(0.020,0.050,0.080)$ & $(0.020,0.040,0.070)$ & $(0.060,0.090,0.110)$ & $(0.070,0.100,0.120)$ & $(0.000,0.000,0.000)$ \\
\hline
\end{tabular}

\section{Table(iii). The fuzzy Total-relation Matrix}

\begin{tabular}{|c|c|c|c|c|c|c|c|c|c|c|}
\hline & H1 & H2 & H3 & H4 & H5 & H6 & H7 & H8 & H9 & H10 \\
\hline H1 & $(0.042,0.185,0.928)$ & $(0.098,0.270,1.043)$ & $(0.079,0.253,1.057)$ & $(0.037,0.189,0.911)$ & $(0.065,0.213,0.944)$ & $(0.068,0.209,0.915)$ & $(0.055,0.189,0.921)$ & $(0.132,0.315,1.099)$ & $(0.113,0.296,1.097)$ & $(0.096,0.265,1.051)$ \\
\hline $\mathrm{H} 2$ & $(0.115,0.309,1.145)$ & $(0.050,0.223,1.066)$ & $(0.105,0.305,1.180)$ & $(0.078,0.261,1.045)$ & $(0.062,0.243,1.047)$ & $(0.065,0.238,1.023)$ & $(0.097,0.269,1.064)$ & $(0.140,0.351,1.215)$ & $(0.130,0.341,1.214)$ & $(0.085,0.281,1.148)$ \\
\hline H3 & $(0.071,0.271,1.116)$ & $(0.108,0.309,1.168)$ & $(0.053,0.230,1.084)$ & .084,0.269,1.058) & $.074,0.249,1.042)$ & $(0.122,0.294,1.050)$ & $(0.099,0.274,1.06$ & $(0.114,0.330,1.21$ & $(0.142,0.356,1.21$ & $(0.106,0.303,1.167)$ \\
\hline H4 & $(0.088,0.265,1.057)$ & $(0.107,0.286,1.099)$ & $(0.086,0.268,1.096)$ & $(0.033,0.172,0.896)$ & $(0.062,0.226,0.978)$ & $(0.040,0.188,0.932)$ & $(0.053,0.212,0.972)$ & $(0.113,0.305,1.130)$ & $(0.103,0.295,1.129)$ & $(0.076,0.253,1.081)$ \\
\hline H5 & $(0.060,0.248,1.102)$ & $(0.072,0.262,1.139)$ & $(0.101,0.290,1.179)$ & $(0.093,0.265,1.046)$ & $(0.037,0.181,0.964)$ & $(0.099,0.260,1.040)$ & $(0.091,0.256,1.056)$ & $(0.095,0.297,1.197)$ & $(0.087,0.289,1.179)$ & $(0.079,0.264,1.146)$ \\
\hline H6 & $(0.087,0.289,1.131)$ & $(0.099,0.304,1.167)$ & $(0.136,0.340,1.200)$ & $(0.092,0.280,1.065)$ & $(0.109,0.293,1.082)$ & $(0.040,0.190,0.951)$ & $(0.072,0.252,1.058)$ & $(0.116,0.335,1.219)$ & $(0.125,0.343,1.217)$ & $(0.106,0.306,1.175)$ \\
\hline H7 & $(0.096,0.283,1.145)$ & $(0.090,0.280,1.174)$ & $(0.110,0.300,1.198)$ & $(0.065,0.240,1.054)$ & $(0.102,0.273,1.080)$ & $(0.083,0.246,1.049)$ & $(0.035,0.174,0.973)$ & $(0.070,0.275,1.192)$ & $(0.089,0.292,1.208)$ & $(0.089,0.276,1.173)$ \\
\hline H8 & $(0.118,0.304,1.142)$ & $(0.110,0.300,1.170)$ & $(0.082,0.275,1.169)$ & $(0.074,0.249,1.043)$ & $(0.093,0.265,1.077)$ & $(0.053,0.219,1.013)$ & $(0.084,0.250,1.054)$ & $(0.052,0.230,1.105)$ & $(0.098,0.302,1.195)$ & $(0.080,0.268,1.153)$ \\
\hline H9 & $(0.123,0.337,1.205)$ & $(0.124,0.342,1.235)$ & $(0.115,0.335,1.243)$ & $(0.132,0.330,1.134)$ & $(0.106,0.303,1.136)$ & $(0.081,0.270,1.085)$ & $(0.112,0.301,1.135)$ & $(0.133,0.366,1.288)$ & $(0.067,0.274,1.179)$ & $(0.130,0.343,1.242)$ \\
\hline H10 & $(0.096,0.275,1.094)$ & $(0.071,0.253,1.105)$ & $(0.078,0.262,1.127)$ & $(0.091,0.257,1.023)$ & $(0.082,0.246,1.023)$ & $(0.050,0.208,0.975)$ & $(0.053,0.204,0.991)$ & $(0.104,0.299,1.162)$ & $(0.112,0.305,1.169)$ & $(0.039,0.191,1.021)$ \\
\hline
\end{tabular}


Table(iv). The crisp Total-relation Matrix

\begin{tabular}{|c|c|c|c|c|c|c|c|c|c|c|}
\hline & H1 & H2 & H3 & H4 & H5 & H6 & H7 & H8 & H9 & H10 \\
\hline H1 & 0.311 & 0.396 & 0.385 & 0.31 & 0.335 & 0.327 & 0.313 & 0.441 & 0.424 & 0.394 \\
\hline H2 & 0.439 & 0.362 & 0.442 & 0.385 & 0.371 & 0.363 & 0.395 & 0.484 & 0.473 & 0.419 \\
\hline H3 & 0.404 & 0.443 & 0.371 & 0.392 & 0.376 & 0.411 & 0.399 & 0.466 & 0.484 & 0.439 \\
\hline H4 & 0.393 & 0.417 & 0.402 & 0.294 & 0.349 & 0.312 & 0.337 & 0.437 & 0.427 & 0.389 \\
\hline H5 & 0.385 & 0.403 & 0.432 & 0.389 & 0.313 & 0.384 & 0.384 & 0.44 & 0.429 & 0.406 \\
\hline H6 & 0.42 & 0.438 & 0.472 & 0.402 & 0.415 & 0.316 & 0.38 & 0.471 & 0.474 & 0.442 \\
\hline H7 & 0.42 & 0.422 & 0.442 & 0.371 & 0.401 & 0.374 & 0.309 & 0.422 & 0.435 & 0.419 \\
\hline H8 & 0.436 & 0.437 & 0.418 & 0.376 & 0.394 & 0.347 & 0.379 & 0.375 & 0.441 & 0.41 \\
\hline H9 & 0.467 & 0.476 & 0.472 & 0.45 & 0.429 & 0.395 & 0.429 & 0.503 & 0.417 & 0.478 \\
\hline H10 & 0.406 & 0.392 & 0.402 & 0.38 & 0.372 & 0.333 & 0.335 & 0.437 & 0.441 & 0.331 \\
\hline
\end{tabular}


Figures

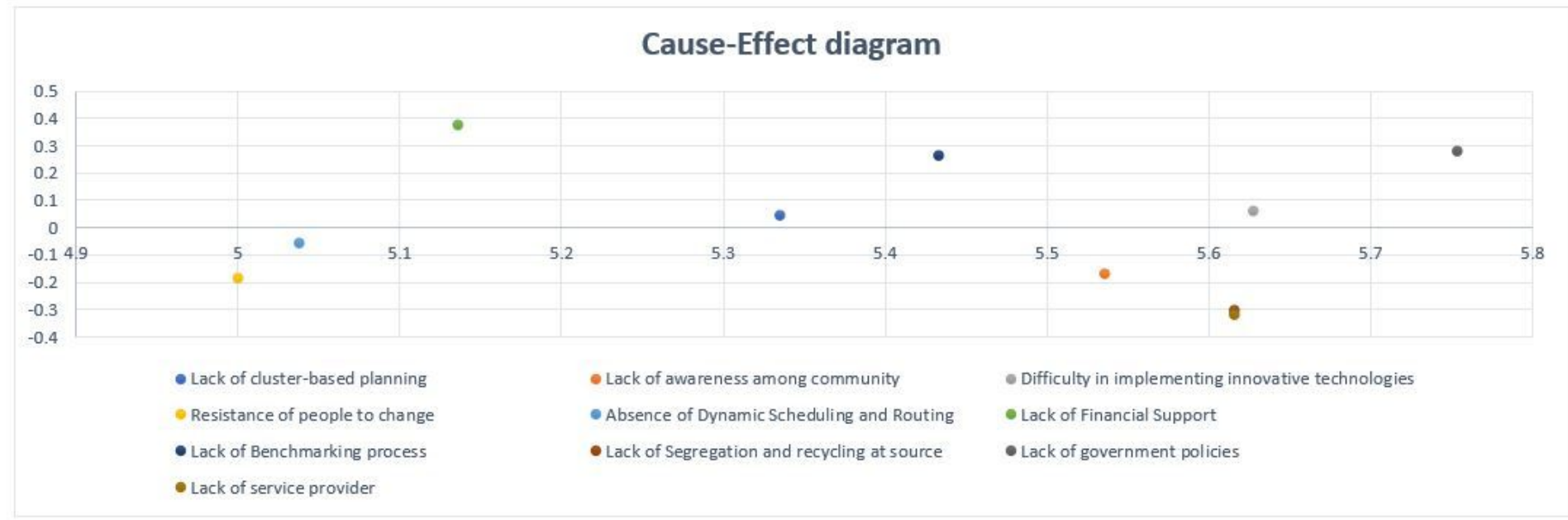

\section{Figure 1}

Cause-effect diagram for government project's perspective

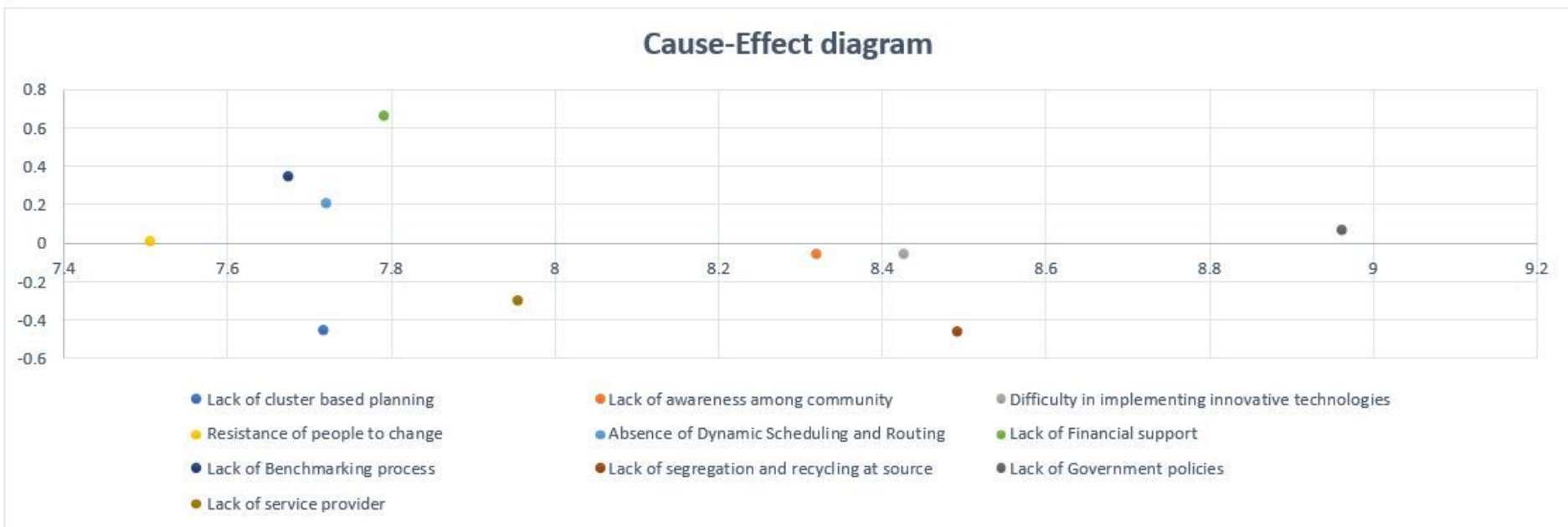

\section{Figure 2}

The cause-effect diagram for technology contributor perspective 
Comparison of cause-effect barriers between Government and Technology perspective

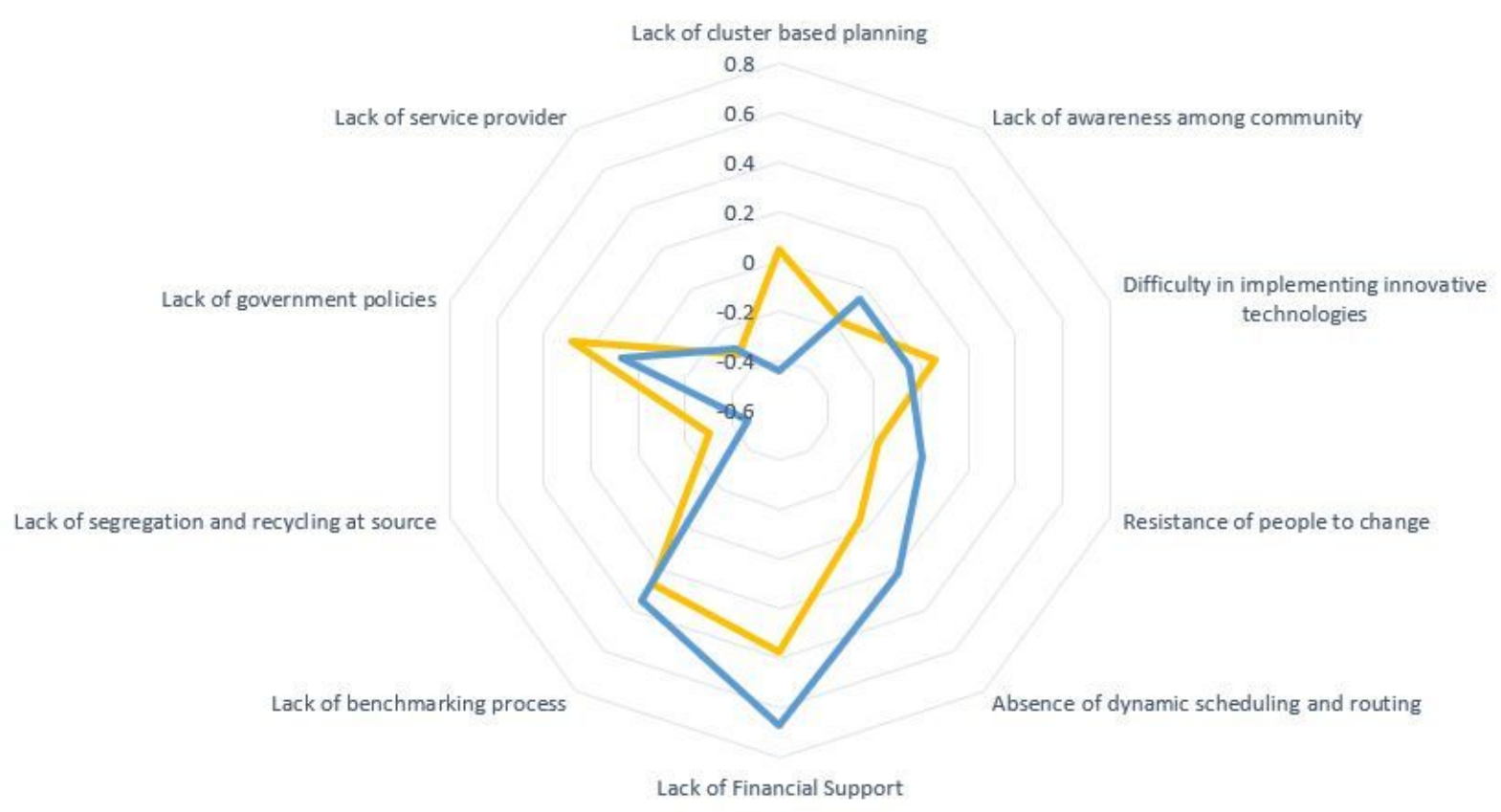

Figure 3

Cause-effect relationship among the barriers from both perception 